\title{
The apolipoprotein receptor LRP3 compromises APP levels
}

\author{
Inmaculada Cuchillo-Ibañez 1,2,3* $\mathbb{0}$, Matthew P. Lennol ${ }^{1,2}$, Sergio Escamilla1,2, Trinidad Mata-Balaguer ${ }^{1,2}$, \\ Lucía Valverde-Vozmediano ${ }^{1}$, Inmaculada Lopez-Font ${ }^{1,2,3}$, Isidro Ferrer ${ }^{2,4}$ and Javier Sáez-Valero ${ }^{1,2,3^{*}}$
}

\begin{abstract}
Background: Members of the low-density lipoprotein (LDL) receptor family are involved in endocytosis and in transducing signals, but also in amyloid precursor protein (APP) processing and $\beta$-amyloid secretion. ApoER2/LRP8 is a member of this family with key roles in synaptic plasticity in the adult brain. ApoER2 is cleaved after the binding of its ligand, the reelin protein, generating an intracellular domain (ApoER2-ICD) that modulates reelin gene transcription itself. We have analyzed whether ApoER2-ICD is able to regulate the expression of other LDL receptors, and we focused on LRP3, the most unknown member of this family. We analyzed LRP3 expression in middle-aged individuals (MA) and in cases with Alzheimer's disease (AD)-related pathology, and the relation of LRP3 with APP.

Methods: The effects of full-length ApoER2 and ApoER2-ICD overexpression on protein levels, in the presence of recombinant reelin or A 442 peptide, were evaluated by microarray, GRT-PCRs, and western blots in SH-SY5Y cells. LRP3 expression was analyzed in human frontal cortex extracts from MA subjects (mean age $51.8 \pm 4.8$ years) and AD-related pathology subjects [Braak neurofibrillary tangle stages I-II, 68.4 \pm 8.8 years; III-IV, $80.4 \pm 8.8$ years; V-VI, $76.5 \pm 9.7$ years] by 9 RT $-P C R s$ and western blot; LRP3 interaction with other proteins was assessed by immunoprecipitation. In CHO cells overexpressing LRP3, protein levels of full-length APP and fragments were evaluated by western blots. Chloroquine was employed to block the lysosomal/autophagy function.

Results: We have identified that ApoER2 overexpression increases LRP3 expression, also after reelin stimulation of ApoER2 signaling. The same occurred following ApoER2-ICD overexpression. In extracts from subjects with AD-related pathology, the levels of LRP3 mRNA and protein were lower than those in MA subjects. Interestingly, LRP3 transfection in CHO-PS70 cells induced a decrease of full-length APP levels and APP-CTF, particularly in the membrane fraction. In cell supernatants, levels of APP fragments from the amyloidogenic (SAPPa) or non-amyloidogenic (SAPP 3 ) pathways, as well as $A \beta$ peptides, were drastically reduced with respect to mock-transfected cells. The inhibitor of lysosomal/ autophagy function, chloroquine, significantly increased full-length APP, APP-CTF, and SAPPa levels.
\end{abstract}

Conclusions: ApoER2/reelin signaling regulates LRP3 expression, whose levels are affected in AD; LRP3 is involved in the regulation of APP levels.

Keywords: SAPP, ApoER2, ApoER2-ICD, Beta-amyloid, Alzheimer's disease, Chloroquine, Differential centrifugation, Autophagy

\footnotetext{
*Correspondence: icuchillo@umh.es; j.saez@umh.es

${ }^{1}$ Instituto de Neurociencias de Alicante, Universidad Miguel Hernández de Elche-CSIC, Sant Joan d'Alacant, Spain

${ }^{2}$ Centro de Investigación Biomédica en Red sobre Enfermedades Neurodegenerativas (CIBERNED), Madrid, Spain

Full list of author information is available at the end of the article
}

\section{Introduction}

The members of the family of low-density lipoprotein (LDL) receptors are endocytic receptors that mediate the uptake of lipoproteins and have been classically studied for their role in cholesterol transport and metabolism. Robust evidence indicates that LDL receptor family original author(s) and the source, provide a link to the Creative Commons licence, and indicate if changes were made. The images or other third party material in this article are included in the article's Creative Commons licence, unless indicated otherwise in a credit line to the material. If material is not included in the article's Creative Commons licence and your intended use is not permitted by statutory regulation or exceeds the permitted use, you will need to obtain permission directly from the copyright holder. To view a copy of this licence, visit http://creativecommons.org/licenses/by/4.0/. The Creative Commons Public Domain Dedication waiver (http://creativeco mmons.org/publicdomain/zero/1.0/) applies to the data made available in this article, unless otherwise stated in a credit line to the data. 
members are involved in synaptic plasticity regulation and neuronal migration (extensively reviewed in [1-6]). LDL receptors are related to Alzheimer's disease (AD) pathogenesis as receptors of apolipoprotein $\mathrm{E}$ (apoE) [7], being the $A P O E 4$ variant the largest known genetic risk factor for late-onset sporadic $\mathrm{AD}[8,9]$. Additionally, several members of the LDL receptor family are able to modulate the amyloid precursor (APP) proteolytic processing, either by regulation of the generation of the $\beta$-amyloid peptide (A $\beta$ ) or through $A \beta$ clearance [10-13].

An important member of the LDL receptor family, ApoER2/LRP8, can exert a modulatory effect in transcriptional expression. ApoER2 interaction with its ligand, the reelin protein, drives to a sequential proteolytic processing, resulting in the cleavage of the receptor by $\alpha$-secretase, which generates a membrane-tethered C-terminal fragment (ApoER2-CTF), followed by the cleavage by $\gamma$-secretase. The action of $\gamma$-secretase generates an intracellular domain fragment (ApoER2-ICD) capable of decreasing the expression of reelin mRNA [14, 15]. Using the same brain extracts as in [14], we found later that the generation of ApoER2-CTF appeared lower and, accordingly, reelin expression resulted higher with respect to those in control brain extracts [16].

In this study, we have further explored the modulatory transcriptional activity of ApoER2/reelin signaling, and we have observed that this pathway can modulate the expression of the LDL-related protein 3 (LRP3). LRP3 is probably the most unknown member of a new subfamily of LDL receptors [17], whose precise role in the central nervous system is still undetermined. We have estimated LRP3 expression in the frontal cortex of middle-aged (MA) individuals and in cases with Alzheimer's disease (AD)-related pathology, and after overexpression in $\mathrm{CHO}$ cells. We have demonstrated that LRP3 is able to modulate APP expression.

\section{Material and methods}

\section{Human brain samples}

This study was approved by the ethics committee of Universidad Miguel Hernández de Elche, Spain, and it was carried out in accordance with the WMA Declaration of Helsinki. Brain samples (frontal cortex; see Table 1) were obtained from the Brain Bank of the Institute of Neuropathology, Bellvitge University Hospital. Cases with AD-related pathology were considered those showing neurofibrillary tangles (NFT) and/or senile plaques with the distribution established by Braak and Braak at the post-mortem neuropathological examination [18]. These were categorized as Braak NFT stages I-II $n=14$, 1 female/13 males, $68.4 \pm 8.8$ years; Braak stages III-IV, $n=14,7$ females $/ 7$ males, $80.4 \pm 8.2$ years; and Braak stages V-VI, $n=12,5$ females/7 males, $76.5 \pm 9.7$ years. Cases at NFT stages I-II showed no or moderate numbers of senile plaques (mostly scores 0 and $\mathrm{A}$ ); cases at stages III-IV usually had moderate numbers of senile plaques (mostly score B); cases at stages V-VI had heavy senile plaque burden (mostly score C; Table 1 ). Cases at stages I, II, and III did not have cognitive impairment; three cases at stage IV had moderate cognitive impairment, and cases at stages V and VI had suffered from dementia. Special care was taken not to include cases with combined pathologies to avoid bias in the pathological series. Samples from middle-aged (MA) subjects ( 3 females/ 8 males; average age $51.8 \pm 4.8$ years) corresponded to individuals with no neurological diseases and no evidence of NFTs and senile plaques. The mean postmortem interval of the tissue was $\sim 8 \mathrm{~h}$ in all cases, with no significant difference between the groups.

A major concern in the design of the study is the age of the different groups of human cases. MA individuals are younger $(51.8 \pm 4.8$ years) when compared with cases with AD-related pathology (NFT I-II 68.4 \pm 8.8 , III-IV $80.4 \pm 8.2$, and V-VI $76.5 \pm 9.7$ ). This selection is due to the fact that the majority of individuals aged 65 years or older have stages I-III of NFT pathology, and, therefore, it is difficult to have samples of age-matched controls without AD-related pathology and morbidities considered in the selection of NFT series that could have an impact on the results [20].

\section{Cell cultures}

SH-SY5Y cells, a human neuroblastoma cell line, were seeded at a density of $1 \times 10^{5}$ cells/well in 6-well plates and cultured in Dulbecco's modified Eagle medium (DMEM) supplemented with Glutamax (GIBCO Thermo Fisher Scientific, Rockford, USA), 1\% heat-inactivated fetal bovine serum (FBS), penicillin $(100 \mathrm{U} / \mathrm{ml})$, and streptomycin $(100 \mu \mathrm{g} / \mathrm{ml})$ in a $5 \% \mathrm{CO}_{2}$ incubator. To neuro-differentiate the cells, all-trans-retinoic acid (RA, Sigma-Aldrich Co, MO, USA) was employed. RA enhances neuronal markers, reelin and ApoER2 expression $[21,22]$. Ten micromolar RA diluted in DMEM with $1 \%$ FBS was added every 2 days. After 6 days, cells were treated with recombinant reelin, $12 \mu \mathrm{g} / \mathrm{ml}$ for $24 \mathrm{~h}$. Other cells were treated with suspensions of $\beta$-amyloid 1-42 $\left(\mathrm{A} \beta_{42}\right)$ or scrambled control peptide (A $\beta$ sc; AIAEGDSHVLKEGAYMEIFDVQGHVFGGKIFRVVDLGSHNVA) (both from Anaspec Peptide, Eurogentec) in DMEM with $1 \%$ FBS, for two consecutive days without changing the media, at a final concentration of $500 \mathrm{nM}, 1 \mu \mathrm{M}$, or $5 \mu \mathrm{M}$.

Non-differentiated SH-SY5Y cells were transfected with Lipofectamine 3000 (ThermoFisher) following manufacturer's instructions, with a construct encoding 
Table 1 Human samples

\begin{tabular}{|c|c|c|c|c|c|}
\hline & Age (y) & Gender & PM (h) & SP & ApoE \\
\hline \multicolumn{6}{|l|}{ MA NFT } \\
\hline \multirow[t]{11}{*}{0} & 46 & f & 9.5 & 0 & $\varepsilon 2 / \varepsilon 3$ \\
\hline & 46 & $\mathrm{~m}$ & 15 & & $\varepsilon 3 / \varepsilon 4$ \\
\hline & 47 & $\mathrm{~m}$ & 5 & & $\varepsilon 3 / \varepsilon 3$ \\
\hline & 49 & $\mathrm{~m}$ & 7.5 & & $\varepsilon 3 / \varepsilon 3$ \\
\hline & 50 & $\mathrm{~m}$ & 17 & & $\varepsilon 3 / \varepsilon 3$ \\
\hline & 52 & $\mathrm{~m}$ & 5 & & $\varepsilon 3 / \varepsilon 3$ \\
\hline & 52 & $f$ & 6 & & $\varepsilon 4 / \varepsilon 4$ \\
\hline & 53 & $\mathrm{~m}$ & 7.5 & & $\varepsilon 3 / \varepsilon 3$ \\
\hline & 56 & $\mathrm{~m}$ & 4 & & $\varepsilon 2 / \varepsilon 3$ \\
\hline & 59 & $\mathrm{~m}$ & 6,5 & & $\varepsilon 3 / \varepsilon 3$ \\
\hline & 60 & $f$ & 11.5 & & $\varepsilon 3 / \varepsilon 3$ \\
\hline \multicolumn{6}{|l|}{ AD NFT } \\
\hline \multirow[t]{4}{*}{ Braak I } & 53 & $\mathrm{~m}$ & 6.25 & A & $\varepsilon 3 / \varepsilon 4$ \\
\hline & 64 & $\mathrm{~m}$ & 8.5 & 0 & $\varepsilon 3 / \varepsilon 3$ \\
\hline & 67 & $\mathrm{~m}$ & 14.5 & 0 & $\varepsilon 3 / \varepsilon 3$ \\
\hline & 68 & $\mathrm{~m}$ & 11 & 0 & $\varepsilon 2 / \varepsilon 3$ \\
\hline \multirow[t]{10}{*}{ Braak II } & 57 & $m$ & 4.5 & 0 & $\varepsilon 3 / \varepsilon 4$ \\
\hline & 60 & $f$ & 9.5 & A & $\varepsilon 3 / \varepsilon 3$ \\
\hline & 65 & $\mathrm{~m}$ & 16.5 & 0 & $\varepsilon 3 / \varepsilon 3$ \\
\hline & 67 & $\mathrm{~m}$ & 7.25 & 0 & $\varepsilon 3 / \varepsilon 4$ \\
\hline & 69 & $\mathrm{~m}$ & 3.5 & $A$ & $\varepsilon 3 / \varepsilon 4$ \\
\hline & 72 & $\mathrm{~m}$ & 6.25 & A & $\varepsilon 3 / \varepsilon 4$ \\
\hline & 74 & $\mathrm{~m}$ & 5.5 & A & $\varepsilon 2 / \varepsilon 3$ \\
\hline & 78 & $\mathrm{~m}$ & 16 & 0 & $\varepsilon 3 / \varepsilon 3$ \\
\hline & 78 & $\mathrm{~m}$ & 10.75 & B & $\varepsilon 3 / \varepsilon 4$ \\
\hline & 86 & $\mathrm{~m}$ & 5.5 & $A$ & $\varepsilon 2 / \varepsilon 3$ \\
\hline \multirow[t]{9}{*}{ Braak III } & 68 & $f$ & 4.5 & A & $\varepsilon 3 / \varepsilon 3$ \\
\hline & 71 & $\mathrm{~m}$ & 7.5 & 0 & $\varepsilon 2 / \varepsilon 3$ \\
\hline & 73 & $\mathrm{~m}$ & 4 & 0 & $\varepsilon 3 / \varepsilon 3$ \\
\hline & 76 & $f$ & 4 & B & $\varepsilon 3 / \varepsilon 3$ \\
\hline & 77 & $\mathrm{~m}$ & 13.5 & $C$ & $\varepsilon 3 / \varepsilon 4$ \\
\hline & 77 & $\mathrm{~m}$ & 5.5 & A & $\varepsilon 3 / \varepsilon 3$ \\
\hline & 79 & $f$ & 3.5 & $B$ & $\varepsilon 3 / \varepsilon 3$ \\
\hline & 82 & f & 5 & A & $\varepsilon 3 / \varepsilon 3$ \\
\hline & 90 & $f$ & 4 & B & $\varepsilon 3 / \varepsilon 3$ \\
\hline \multirow[t]{5}{*}{ Braak IV } & 79 & $\mathrm{~m}$ & 5 & $A$ & $\varepsilon 4 / \varepsilon 4$ \\
\hline & 81 & $f$ & 5 & C & $\varepsilon 3 / \varepsilon 3$ \\
\hline & 85 & $\mathrm{~m}$ & 14 & $B$ & $\varepsilon 3 / \varepsilon 4$ \\
\hline & 89 & $\mathrm{~m}$ & 3.5 & $B$ & $\varepsilon 3 / \varepsilon 4$ \\
\hline & 99 & $f$ & 5 & B & $\varepsilon 3 / \varepsilon 3$ \\
\hline \multirow[t]{9}{*}{ Braak V } & 72 & $m$ & 2.75 & $C$ & $\varepsilon 3 / \varepsilon 4$ \\
\hline & 73 & $\mathrm{~m}$ & 4.5 & $B$ & $\varepsilon 3 / \varepsilon 4$ \\
\hline & 74 & f & 9 & A & $\varepsilon 3 / \varepsilon 4$ \\
\hline & 75 & $\mathrm{~m}$ & 11.5 & $B$ & $\varepsilon 3 / \varepsilon 4$ \\
\hline & 77 & $\mathrm{~m}$ & 16 & $C$ & $\varepsilon 3 / \varepsilon 3$ \\
\hline & 78 & $m$ & 17 & 0 & $\varepsilon 3 / \varepsilon 3$ \\
\hline & 81 & $f$ & 5.5 & C & $\varepsilon 3 / \varepsilon 4$ \\
\hline & 87 & $\mathrm{~m}$ & 7 & $C$ & $\varepsilon 3 / \varepsilon 3$ \\
\hline & 93 & $\mathrm{~m}$ & 3 & $C$ & $\varepsilon 3 / \varepsilon 3$ \\
\hline
\end{tabular}

Table 1 (continued)

\begin{tabular}{llllll}
\hline & Age (y) & Gender & PM (h) & SP & ApoE \\
\hline BraakVI & 56 & $f$ & 7 & $C$ & $\varepsilon 3 / \varepsilon 3$ \\
& 67 & $f$ & 8 & $C$ & $\varepsilon 3 / \varepsilon 4$ \\
& 86 & $f$ & 20.5 & $C$ & $\varepsilon 3 / \varepsilon 3$
\end{tabular}

Middle-aged (MA) cases and cases with AD-related pathology (AD). Subjects were categorized according to the Braak stage of neurofibrillary tangle (NFT I-VI) and senile plaque staging $(0-C)[18,19]$. Age ( $y$ years), gender ( $m$ male, $f$ female), post-mortem (PM, $h$ hours), SP senile plaques, APOE (APOE alleles, $\varepsilon 2, \varepsilon 3$, and $\varepsilon 4$ )

full-length ApoER2 (pEGFPN1-Mus musculus ApoER2, residues 1-842) and ApoER2-ICD-HA expressing only the cytoplasmic domain (residues 728-842) (both generously provided by Dr W. Rebeck; see ref. [23, 24]), or with GFP/cDNA3.1 as mock transfection as in [14] for $48 \mathrm{~h}$. After $24 \mathrm{~h}$ post-transfection, some CHO-PS70 cells were treated with $10 \mu \mathrm{M}$ chloroquine for another $24 \mathrm{~h}$.

$\mathrm{CHO}$ cells stably overexpressing wild-type human APP (CHO-PS70, [25]) were grown in DMEM ${ }^{\circledR}$ containing 10\% FBS, 0.1\% Puromycin (Sigma-Aldrich), and 0.2\% G418 disulfate salt (Sigma-Aldrich). CHO-PS70 cells were transfected with full-length human LRP3 cDNA (3×FLAG-LRP3 in pCMV7.1; a kind gift from Christine Lavoie, [26]) for $48 \mathrm{~h}$. After $24 \mathrm{~h}$ post-transfection, some CHO-PS70 cells were treated with $10 \mu \mathrm{M}$ chloroquine for $24 \mathrm{~h}$.

\section{Brain membrane-enriched fractions}

Brain cortex samples were homogenized using a polytron Heidolph RZR-1 at 600-800 rpm, in a glass potter applying 10-15 pulses in buffer at $10 \%(\mathrm{w} / \mathrm{v})($ Hepes $1 \mathrm{mM}$, sucrose 0,32 $\mathrm{M}, \mathrm{Cl}_{2} \mathrm{Mg} \mathrm{mM}$, EDTA $1 \mathrm{mM}, \mathrm{NaHCO}_{3}$ $1 \mathrm{mM}$, PMSF, protease inhibitors (Cocktail Complete EDTA free, Roche), antiphosphatase inhibitor (PhosSTOP, Sigma)). The homogenate was centrifuged at 1000 $\times g$ during $20 \mathrm{~min}$ at $4^{\circ} \mathrm{C}$. The supernatant (post-nuclear fraction) was centrifuged at $13000 \times g$ during $15 \mathrm{~min}$ at $4^{\circ} \mathrm{C}$. The supernatant (cytosolic fraction) was aliquoted, and the resulting pellet (membrane-enriched fraction) was resuspended in buffer (Hepes $1 \mathrm{mM}, \mathrm{Cl}_{2} \mathrm{Mg} \mathrm{mM}$, EDTA $1 \mathrm{mM}, \mathrm{NaHCO}_{3} 1 \mathrm{mM}$, PMSF, protease inhibitor cocktail (Sigma-Aldrich), antiphosphatase inhibitor (Sigma-Aldrich)).

In some CHO-PS70 cells, we performed a differential centrifugation. After homogenization of cell extracts in sucrose buffer $(0.32 \mathrm{M}$ sucrose, $10 \mathrm{mM}$ Tris $\mathrm{pH}$ 7.4, EGTA, $1 \mathrm{mM} \mathrm{Na}_{3} \mathrm{VO}_{4}, 5 \mathrm{mM} \mathrm{NaF}, 1 \mathrm{mM}$ EDTA, $1 \mathrm{mM}$ Hepes), the homogenate was centrifuged at $1000 \times g$ for $10 \mathrm{~min}$. The supernatant was centrifuged at $15000 \times g$ for $15 \mathrm{~min}$. The resultant supernatant (fraction containing mainly the plasma membrane and soluble proteins from the cytosol) and the pellet (containing mainly membranes 
from the endoplasmic reticulum, mitochondria, lysosomes, peroxisomes, and endosomes) were quantified and stored.

\section{Microarray analysis}

Gene expression was analyzed $48 \mathrm{~h}$ after transfection with human full-length ApoER2, using microarrays SurePrint G3 Human Microarrays (ID 039494, Agilent Technologies, Spain) and performed by Bioarray SL (http:// www.bioarray.es). The concentration and purity of the total RNA extracted were measured by a NanoDrop spectrophotometer, and RNA quality was determined with the kit R6K Screen Tape (Agilent Technologies, Spain). The estimated RNA integrity number ranged between 9.5 and 9.7. Each sample (four samples and four controls) was labeled with $\mathrm{Cy} 3$ using the One-Color MicroarrayBased Gene Expression Microarrays Analysis v.6.6 (Agilent Technologies, Spain). Data were imported to the linear models for microarray data Bioconductor software (Limma, Marray, affy, pcaMethods and EMA). Raw data were first subjected to background subtraction, then to within-array loess normalization. Finally, across-array normalization was performed. Normalized data were fitted to a linear model. The significance of the gene expression changes was analyzed according to the adjusted $p$ value (adj. $p<0.05)$.

\section{qRT-PCR analysis}

RNA was extracted from human brains, SH-SY5Y cells, or CHO-PS70 cells using the TRIzol ${ }^{\circledR}$ Reagent in the PureLink $^{\mathrm{TM}}$ Micro-to-Midi Total RNA Purification System (Life Technologies, Carlsbad, CA, USA) following the manufacturer's instructions. SuperScript ${ }^{\mathrm{TM}}$ III Reverse Transcriptase (Life Technologies, Carlsbad, CA, USA) was used to synthesize cDNAs from this total RNA $(2 \mu \mathrm{g})$ using random primers according to the manufacturer's instructions. Quantitative PCR amplification was performed on a StepOne ${ }^{\mathrm{TM}}$ Real-Time PCR System (Applied Biosystems, Thermo Fisher Scientific, Rockford, USA) with TaqMan probes specific for human LRP3 (assay ID: HS01041220_m1), LDLR (assay ID: HS00181192_m1) (Applied Biosystems, Thermo Fisher Scientific, Rockford, USA), and human $18 S$ as a housekeeping gene (Applied Biosystems, Thermo Fisher Scientific, Rockford, USA) for the human brain and SH-SY5Y cell samples. In CHO-PS70, mRNA expression was measured with primers for human APP (forward: AAC CAGTGACCATCCAGAAC; reverse: ACTTGTCAG GAACGAGAAGG) and for glyceraldehyde 3-phosphate dehydrogenase (GAPDH, forward: AGAAGGTGGTGA AGCAGGCAT; reverse: AGGTCCACCACTCTGTTG CTGT) to normalize the expression levels of the target gene by the $\Delta \mathrm{Ct}$ method curves.
$A P O E$ genotyping was performed by $q \mathrm{RT}-\mathrm{PCR}$ according to a previously described method [27].

\section{Recombinant reelin}

HEK-293T cells stably transfected with full-length mouse reelin clone pCrl or GFP (mock) (kindly provided by Dr. E. Soriano, Department of Cell Biology, University of Barcelona, Barcelona, Spain) were seeded in $175-\mathrm{cm}^{2}$ flasks at a density of $10 \times 10^{6}$ cells/flask. After 3 days in culture in Optimem, the supernatants were filtered through 0.2$\mu \mathrm{m}$ pores and concentrated with an Amicon Ultra 100kDa size exclusion filter (Merk Millipore, Darmstadt, Germany). For quantification, a coomasie gel was loaded with different volumes of the concentrated supernatants as well as with different bovine serum albumin solutions to perform an extrapolation.

\section{Western blotting}

Brain membrane-enriched fractions, SH-SY5Y extracts, or CHO-PS70 extracts $(30 \mu \mathrm{g})$ were run on SDS-PAGE (7.5\%, $12 \%$, precast $4-15 \%$ gradient, or Tris-tricine $16 \%$ ) after boiling at $98^{\circ} \mathrm{C}$ for 5 min in $6 \times$ Laemmli sample buffer. Proteins were transferred by electrophoresis to nitrocellulose membranes and detected with antibodies against the C-terminal of LRP3 (mouse, 1:100, SigmaAldrich, St. Louis, MO, USA), N-terminal of LRP3 (rabbit, 1:100, Sigma-Aldrich), Flag (mouse, 1:1000, Sigma-Aldrich), C-terminal of LDLR (rabbit, 1:200, Sigma-Aldrich), C-terminal of ApoER2 (rabbit, 1: 2000, Abcam, Cambridge, UK), C-terminal of APP (rabbit, 1: 2000, Sigma-Aldrich), N-terminal of APP (rabbit, 1: 2000, Sigma-Aldrich), sAPP $\alpha$ (mouse, 1:1000; IBL, Hamburg, Germany), sAPP $\beta$ (rabbit 1:1000; IBL), LC3B (rabbit, 1:2000; Abcam), or $\alpha$-tubulin (1:4000, Sigma-Aldrich) as a loading control. Primary antibody binding was visualized with fluorescent secondary antibodies (IRDye, 1: 10000), and images were acquired using an Odyssey CLx Infrared Imaging system (LI-COR Biosciences $\mathrm{GmbH}$ ). Representative whole blots are shown as Supp Fig. 1.

\section{Immunoprecipitation}

Brain extracts $(100 \mu \mathrm{L})$ or CHO-PS70 extracts $(50 \mu \mathrm{L})$ were incubated on a roller for $2.5 \mathrm{~h}$ at room temperature with $100 \mu \mathrm{L}$ of magnetic beads (Dynabeads, Merck Millipore) coupled to the C-terminal LRP3 (mouse, Sigma-Aldrich) for brain extracts, C-terminal APP (rabbit, Biolegend) for CHO-PS170 extracts, or mouse/rabbit IgG (negative controls). The input, bound, and unbound fractions were analyzed by western blotting using specific antibodies.

\section{Immunofluorescence}

CHO-PS70 cells overexpressing LRP3-flag were washed with cold Hank-buffered salt solution and fixed with $4 \%$ 
Table 2 Expression of genes upregulated by full-length ApoER2 overexpression

\begin{tabular}{|c|c|c|c|c|c|}
\hline Symbol & Gene name & Genomic location & Function & $\log \mathrm{FC}$ & $\operatorname{adj} p$ \\
\hline LRP3 & $\begin{array}{l}\text { Low-density lipoprotein receptor- } \\
\text { related protein } 3\end{array}$ & $19 q 13.11$ & $\begin{array}{l}\text { Internalization of lipophilic molecules and/or signal } \\
\text { transduction } \\
\text { Precise role is unclear }\end{array}$ & 0.48 & 0.047 \\
\hline LDLR & Low-density lipoprotein receptor & 19p13.2 & Mediates endocytosis of cholesterol-rich LDL & 0.43 & 0.018 \\
\hline APOL1 & apolipoprotein $\mathrm{L}, 1$ & $22 q 12.3$ & Minor apoprotein component of HDL & 1.28 & 0.003 \\
\hline INSIG1 & Insulin-induced gene 1 & $7 q 36.3$ & Regulation of cholesterol cell concentration & 0.72 & 0.001 \\
\hline DHCR24 & 24-Dehydrocholesterol reductase & $1 \mathrm{p} 32.3$ & Cholesterol metabolic process & 0.35 & 0.008 \\
\hline MVK & Mevalonate kinase & $12 q 24.11$ & Cholesterol metabolic process & 0.33 & 0.019 \\
\hline
\end{tabular}

Genes associated with lipid binding and transport, and cholesterol metabolism, whose transcripts were upregulated in ApoER2 overexpressing SH-SY5Y cells compared with control cells transfected with an empty vector. The expression of the genes was analyzed on DNA microarrays. The fold change (logFC) in gene expression between samples and controls, as well the adj $p$ ( $p$ value adjusted for multiple testing) is indicated

paraformaldehyde and $0.1 \mathrm{M}$ EGTA for $10 \mathrm{~min}$. To stain the plasma membrane, cells were incubated with WGAFITC (WGA: lectin from Triticum vulgaris, FITC (fluorescein) conjugate, Sigma-Aldrich) for $15 \mathrm{~min}$ at room temperature, and the nonspecific sites were blocked with $10 \%(\mathrm{w} / \mathrm{v})$ bovine serum albumin for $30 \mathrm{~min}$. No permeabilization steps were included before or during the incubation with the primary antibodies. Cells were incubated with a primary antibody against Flag (1:200; mouse; Sigma-Aldrich) for $1 \mathrm{~h}$, followed by the secondary antibody (1:200, Cy5 anti-mouse; GE-Healthcare) for $1 \mathrm{~h}$. After washes with PBS, cells were incubated briefly with Hoechst dye to label nuclei (Invitrogen). Pictures were acquired in a Leica SPEII upright TCL-SL confocal microscope using an oil-immersion $40 \times$ objective

\section{Double-labeling immunofluorescence and confocal microscopy}

The frontal cortex and hippocampus of 14 cases at Braak NFT stages $0-I, I V$, and V-VI and senile plaque stages $0-\mathrm{C}$ were used in the study. Formalin-fixed, paraffinembedded, de-waxed sections, $4 \mu \mathrm{m}$ thick, were stained with a saturated solution of Sudan black B (Merck) for 15 min to block autofluorescence of lipofuscin granules present in cell bodies and then rinsed in $70 \%$ ethanol and washed in distilled water. The sections were boiled in citrate buffer to enhance antigenicity and blocked for $30 \mathrm{~min}$ at room temperature with $10 \%$ fetal bovine serum diluted in PBS. Then, the sections were incubated at $4^{\circ} \mathrm{C}$ overnight with combinations of primary antibodies: LRP3-C-term (Sigma-Aldrich, ref SAB1300316, polyclonal rabbit, diluted at 1:50) and apoER2 (Invitrogen, ref MA5-36130, mouse monoclonal, diluted 1:50). After washing, the sections were incubated with Alexa488 or Alexa546 (1:400, Molecular Probes) fluorescent secondary antibodies against the corresponding host species. Nuclei were stained with DRAQ5 ${ }^{\mathrm{TM}}$ (1:2000, Biostatus). After washing, the sections were mounted in an
Immuno-Fluore mounting medium (ICN Biomedicals), sealed, and dried overnight. Sections were examined with a Leica TCS-SL confocal microscope.

\section{Statistical analysis}

The distribution of data was tested for normality using a D'Agostino-Pearson test. ANOVA was used for parametric variables and the Kruskal-Wallis test for non-parametric variables for comparison between groups. A Student's $t$-test for parametric variables and a Mann-Whitney $U$ test for non-parametric variables were employed for comparison between two groups and for determining $p$ values. For data analyzed using unpaired Student's $t$-test, a Welch's correction was employed in data with different standard deviations. Correlation between variables was assessed by linear regression analyses. The results are presented as the means $\pm \mathrm{SE}$, and all the analyses were performed using GraphPad Prism (version 7; GraphPad Software, Inc). $p$ value $<0.05$ was considered significant.

\section{Results}

\section{ApoER2 overexpression increases the expression of LRP3}

SH-SY5Y cells were transfected with full-length ApoER2, and after $48 \mathrm{~h}$, a microarray was performed. Among the genes affected, we focused on the analysis of LDL receptors and apolipoprotein-related genes (Table 2). The receptors LRP3 and LDLR appeared significantly upregulated, both of which are members of the LDL receptor family. Upregulation of LRP3 was confirmed by $q$ RT-PCR, with a significant increase in mRNA LRP3 level compared to its expression in non-transfected cells. However, increments in LDLR mRNA expression were not significant when assessed by $q$ RT-PCR (Fig. 1a).

Although SH-SY5Y cells secrete reelin to the media and it can act in a paracrine mode, recombinant reelin was employed to treat overexpressing-ApoER2 cells to potentiate the ApoER2 signaling. This treatment induced ApoER2 cleavage and, consequently, reduced the amount 
A
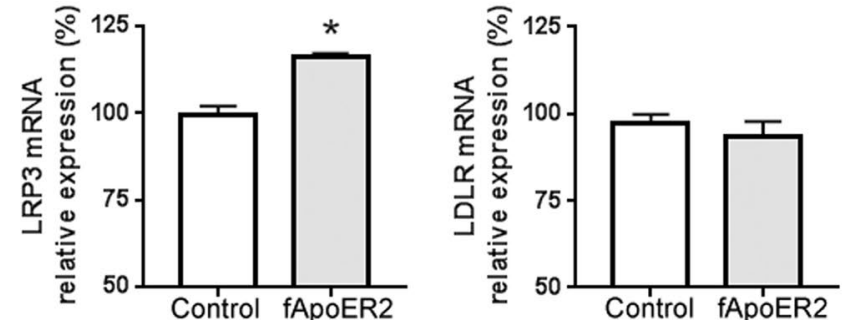

B
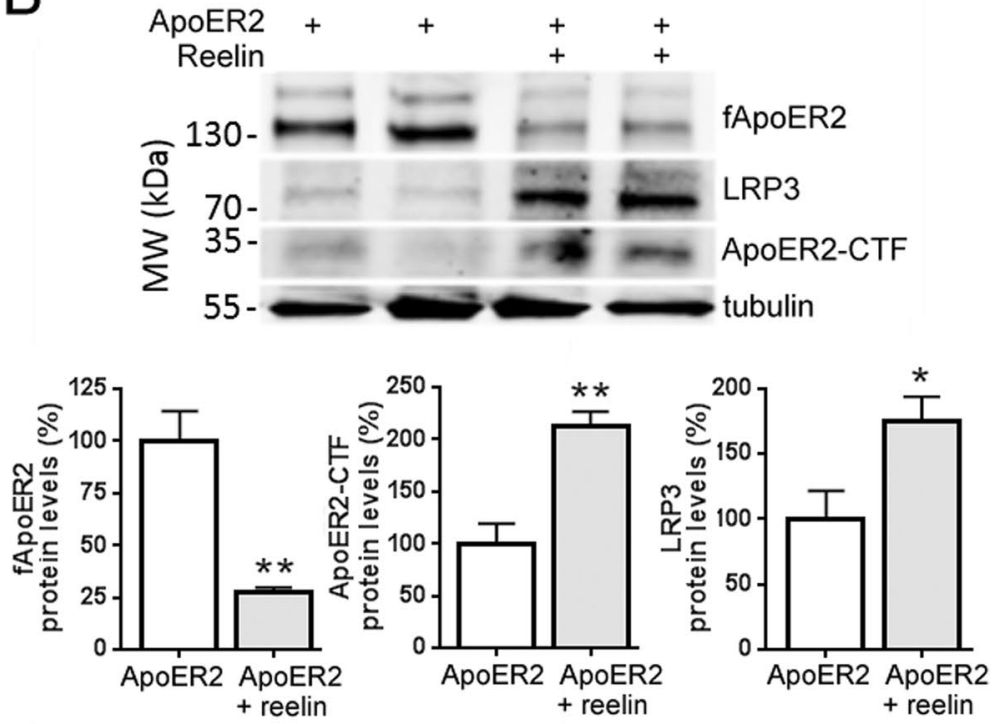

C
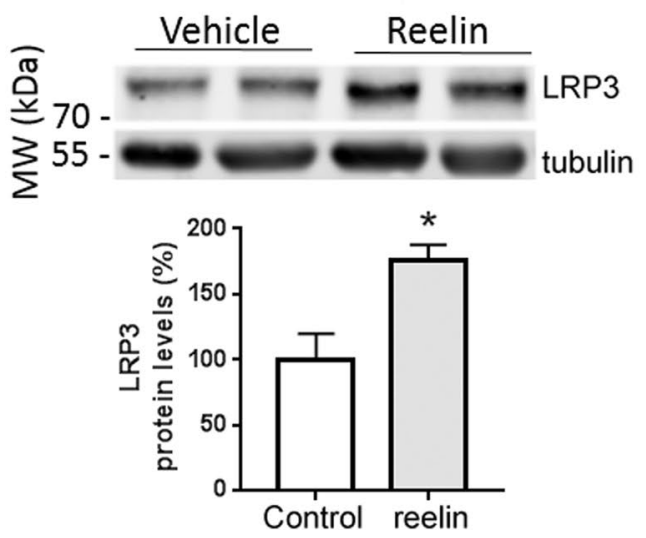

Fig. 1 ApoER2/reelin signaling upregulates LRP3 expression. a qRT-PCR analysis showing expression of LRP3 mRNA and LDLR mRNA after transfection with GFP CDNA (control) and full-length ApoER2 CDNA (fApoER2) in SH-SYSH cells. 18S was used as an internal control for mRNA expression ( $n=10-12$ for each condition, $p<0.001$ for control versus fApoER2; $t$-test with Welch's correction). Note that the $X$ axis begins at $50 \%$. b Quantification and western blot showing the expression of full-length ApoER2, ApoER2-CTF, and LRP3 proteins after fApoER2 transfection and reelin $(12 \mu \mathrm{g} / \mathrm{ml})$ treatment for $24 \mathrm{~h}$ in SH-SY5Y cells. Tubulin was used as an internal control $\left(n=9\right.$ for each condition, ${ }^{* *} p<0.001$ for expression of fApoER2, $t$-test with Welch's correction, and ApoER2-CTF, $t$-test; ${ }^{*} p<0.05$ for expression of LRP3, $t$-test). c Quantification and western blot showing the expression of LRP3 protein after reelin $(12 \mu \mathrm{g} / \mathrm{ml}$ ) treatment for $24 \mathrm{~h}$ or vehicle (Hanks's media) in neuro-differentiated SH-SY5Y cells with retinoic acid ( $n=9$ for each condition, ${ }^{*} p<0.05$ t-test) 


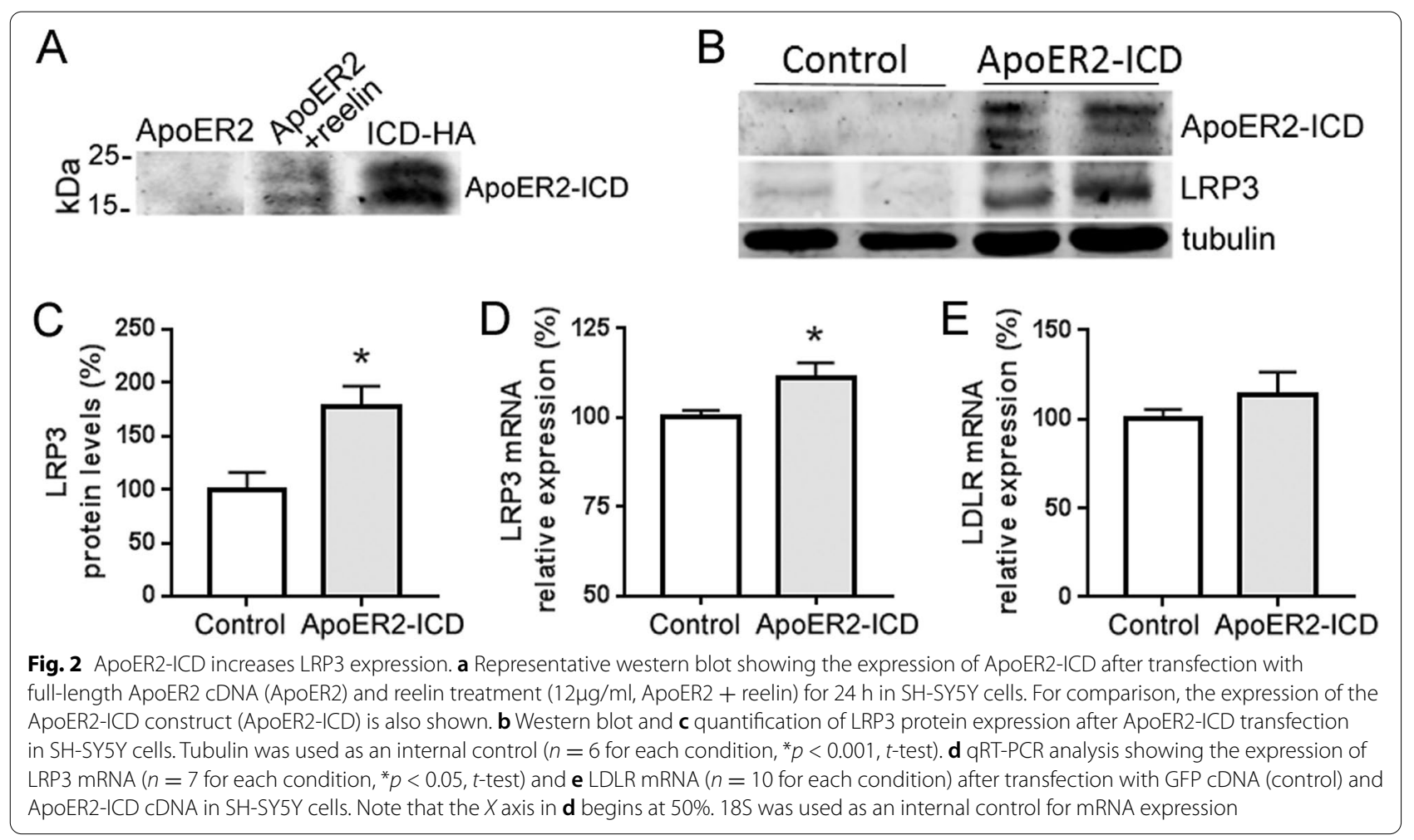

of full-length ApoER2 and increased the generation of the ApoER2-CTF. Importantly, reelin treatment induced an increment of LRP3 protein levels (Fig. 1b). In RA neuro-differentiated SH-SY5Y cells, reelin treatment was also able to induce an increase in LRP3 protein levels compared to non-stimulated cells (Fig. 1c).

\section{Expression of ApoER2-ICD upregulates LRP3 expression}

We considered the possibility that increments of LRP3 expression were induced by ApoER2-ICD, a fragment with transcriptional regulatory activity [14], generated by the proteolytic cleavage of ApoER2-CTF. This small fragment was observed in ApoER2-overexpressing cells after treatment with reelin (Fig. 2a). Thus, we overexpressed a chimeric ApoER2-ICD (amino acid residues 728-842) and measured LRP3 expression. LRP3 mRNA expression and protein levels increased significantly with respect to non-transfected cells (Fig. 2b-d), while LDLR mRNA levels were not significantly affected by ApoER2-ICD (Fig. 2e).

\section{Expression levels of LRP3 in A $\beta 42$-treated cells}

On the contrary to the upregulation of LRP3 mRNA and protein that we observed after overexpression of full-length ApoER2 or ApoER2-ICD, we expected to find less LRP3 expression in A 342 -treated cells, due to the fact that $A \beta$ treatment reduces the generation of
ApoER2-CTF [16]. In agreement with this view, we found that treatment of neuro-differentiated SH-SY5Y cells with $1 \mu \mathrm{M}$ and $5 \mu \mathrm{M} \mathrm{A} \beta 42$ decreased the LRP3 protein levels, but $500 \mathrm{nM}$ did not have the same effect, in comparison to scrambled peptide treatment (control, Fig. 3a). Five micromolar A 342 also reduced LRP3 mRNA expression (Fig. 3b).

\section{Expression levels of LRP3 in AD brain}

Next, we examined LRP3 levels in human frontal cortex extracts. Considering all cases with AD-related pathology, LRP3 mRNA expression was lower with respect to MA subjects $(p=0.02 ; t$-test) (Fig. 4a). However, when cases with AD-related pathology were categorized by Braak NFT stages, the reduction was significant only at Braak stages NFT I-II ( $p=0.03$; $t$-test), while NFT III-IV or NFT V-VI displayed the same trend but failed to reach statistical significance $(p=0.10 ; p=0.15$, respectively, $t$-test). No significant modifications were found between Braak stages NFT I-II and NFT III-IV or NFT V-VI ( $p$ $=0.56 ; p=0.65$, respectively, $t$-test; Fig. $4 \mathrm{~b}$ ). Despite the difference in age between MA and AD-related pathology cases, age did not correlate with LRP3 mRNA in MA ( $n$ $=11 ; R=0.058, p=0.87)$ or AD-related pathology individuals $(n=40 ; R=0.067 ; p=0.68)$.

Gender did not contribute to differences in LRP3 mRNA expression either. The comparison between 


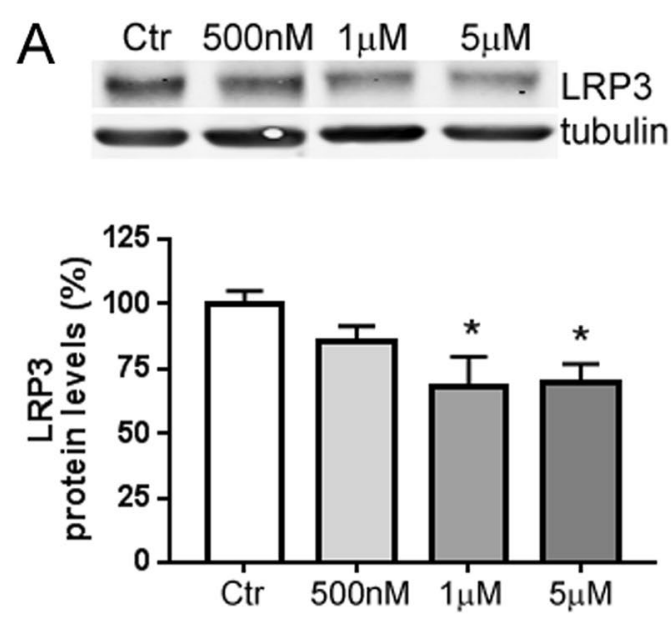

$\mathrm{B}$

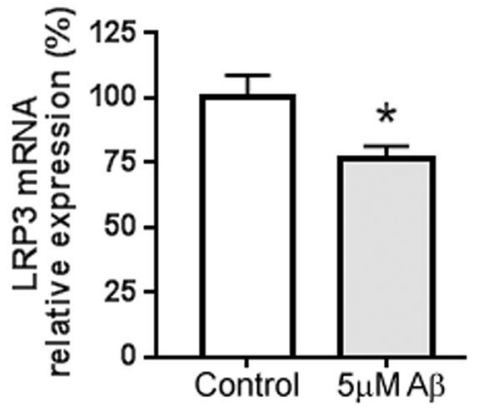

Fig. 3 A 42 reduces LRP3 expression. a Quantification and western blot showing the expression of LRP3 proteins in neuro-differentiated SH-SY5Y cells treated with $5 \mu \mathrm{M} A \beta 42$ or scrambled A 42 (control). Tubulin was used as an internal control ( $n=9$ for each condition, ${ }^{*} p<0.05, t$-test). b qRT-PCR analysis showing expression of LRP3 mRNA in neuro-differentiated SH-SY5Y cells treated with $500 \mathrm{nM}, 1 \mu \mathrm{M}, 5 \mu \mathrm{M}$ A 342 , or scrambled Aß42 (control). 18S was used as an internal control for mRNA expression ( $n=8$ for each condition, $p<0.05$; $t$-test)
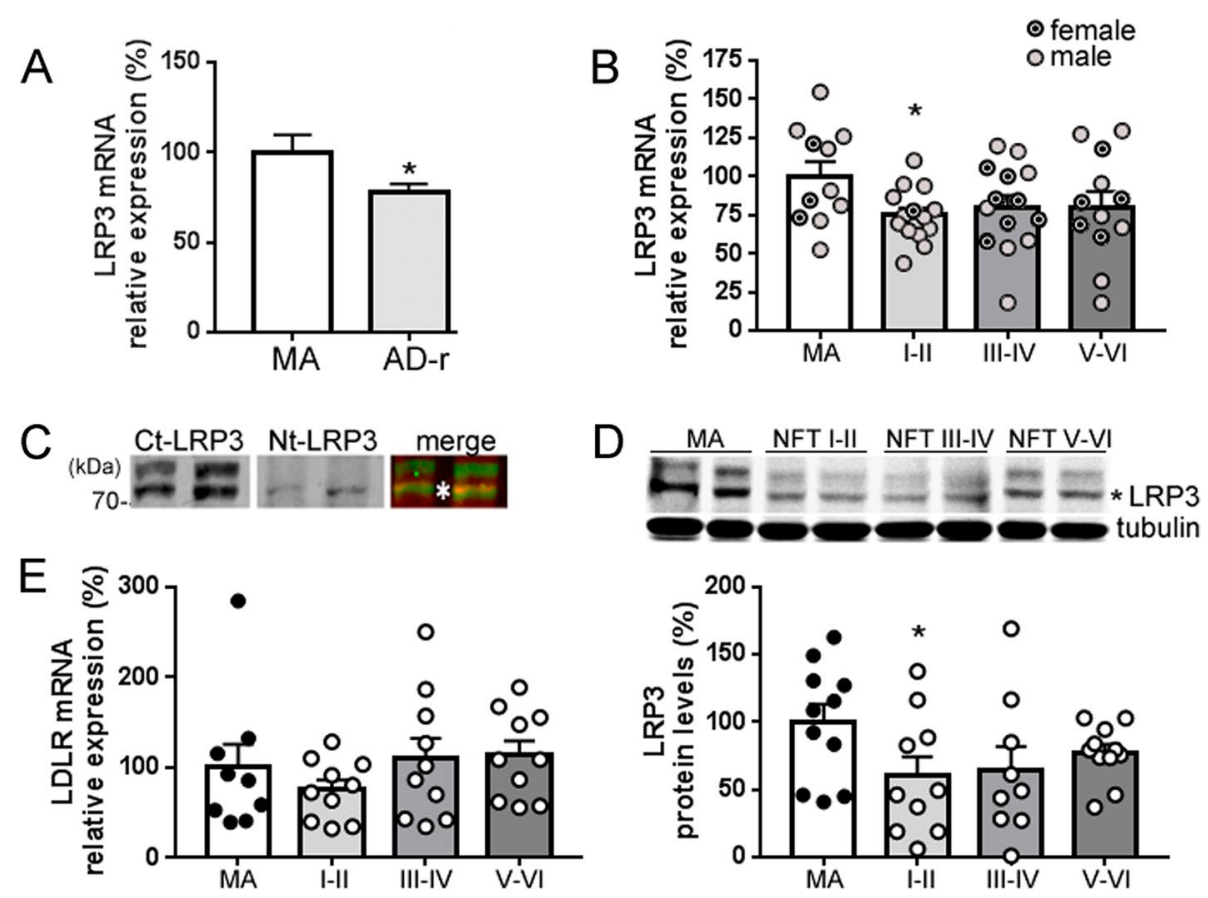

Fig. 4 Low levels of LRP3 in AD frontal cortex. a qRT-PCR analysis showing expression of LRP3 mRNA in brain extracts from MA and Alzheimer's disease-related (AD-r) subjects, and $\mathbf{b}$ categorized by Braak NFT stages (I-II, III-IV, and V-VI). 185 was used as an internal control for mRNA expression $\left(n=11\right.$ for MA, $n=12-14$ for each AD-r Braak stage, ${ }^{*} p<0.05, t$-test for MA $\vee$ AD-r, $t$-test with Welch's correction for MA $\vee$ AD-r I-II). c Western blots showing different LRP3 immunoreactivities in human cortex extracts. Two bands were observed using an anti-C-terminal LRP3, but a single band was observed when an anti-N-terminal LRP3 was used, all between 70 and 100kDa. One of the bands immunoreacted to both antibodies, likely representing the full-length receptor. Accordingly, the overlapping band $\left(^{*}\right)$ was selected for quantification. $\mathbf{d}$ Western blot using an anti-C-terminal LRP3 in brain extracts from MA and AD-r subjects, categorized by Braak's stages (NFT I-II, NFT III-IV, and NFT V-VI) and quantification of the lower band (marked with $\mathrm{a}^{*}$ ). Tubulin was used as an internal control ( $n=11$ for MA, $n=10-11$ for each NFT Braak's stage, ${ }^{*} p<0.05$, Mann-Whitney test). e qRT-PCR analysis showing expression of LDLR mRNA in brain extracts from MA and AD-r subjects, categorized by Braak's stages. 18s was used as an internal control for mRNA expression ( $n=9$ for MA, $n=10$ for each Braak's stage) 
females and males from MA and from AD-related pathology groups was not statistically significative $(p=0.13$, one-way ANOVA). When female values were subtracted from both groups, LRP3 mRNA expression in males was still different between MA and AD-related pathology overall ( $p=0.042, t$-test). However, the difference observed in Braak stages I-II failed to maintain statistical significance, probably due to the smaller sample size ( $p$ $=0.060, t$-test). Braak stages III-IV and V-VI remained without differences in males compared to MA males ( $p=$ 0.20 and $p=0.22$, respectively, $t$-test). The APOE genotype did not account for LRP3 mRNA expression either ( $p=0.47 \varepsilon 4$ carriers $v$ non- $\varepsilon 4$ carrier AD-related cases).

To evaluate LRP3 protein levels in the cortex from MA and cases with AD-related pathology, membraneenriched fractions were isolated from brain samples. Due to the lack of reports about LRP3 in the brain, two antibodies were tested to corroborate the identity of LRP3 immunoreactive bands (Fig. 4c). We found that LRP3 expression levels were lower at Braak stages I-II compared to those in MA individuals $(p=0.048, t$-test, Fig. 4d). No further differences were seen at stages III-IV and V-VI when compared with MA ( $p=0.11$ and $p=$ 0.12 , respectively, $t$-test) and compared with Braak NFT stages I-II ( $p=0.84$ and $p=0.26$ respectively, $t$-test).

The estimated expression of LDLR mRNA was not significantly different between MA individuals and AD-related pathology subjects when the extracts were compared overall ( $p=0.73$ Mann-Whitney) or when compared discriminating Braak stages $(p=0.73$ one-way ANOVA; Fig. 4e).

\section{LRP3 interacts with apoE and APP, but not with reelin in the human brain}

Double-labeling immunofluorescence and confocal resolution showed that the LRP3 antibody recognized small granules localized in the cytoplasm and proximal dendrites of all neurons, and around the nucleus of glial cells in the hippocampus and frontal cortex. ApoER2 antibody also showed small granules in the cytoplasm of neurons and small glial cells. The immunostaining was variable in the MA group and in cases with NFT pathology with marked individual disparities, probably due to the vulnerability of the protein to the pre-mortem status and post-mortem delay (Fig. 5a). This individual variability did not permit any attempt to quantify inter-group immunostaining densitometry.

We also evaluated, by means of immunoprecipitation assays, whether reelin acts as a ligand for LRP3, as it does for ApoER2, in frontal cortex extracts from MA and AD-related pathology cases. Reelin was not co-immunoprecipitated from any brain extracts. We next assessed whether LRP3 interacts with apoE and APP, in the same way as many members of the LDL receptor family do. After immunoprecipitation, both proteins were coimmunoprecipitated with LRP3 in MA and cases with AD-related pathology (Fig. 5b).

\section{LRP3 modulates APP expression levels}

We tested whether LRP3 was able to influence APP processing and $A \beta$ generation in a similar manner to other members of the LDL receptor family. In order to do so, we overexpressed LRP3 in CHO-PS70 cells, a cell line that expresses the wild-type APP770 isoform. LRP3 was located at discrete areas of the soma and in the plasma membrane of CHO-PS70 cells (Fig. 6a). Moreover, LRP3 and APP co-immunoprecipitated in these cells (Fig. 6b). Overexpression of LRP3 did not affect APP mRNA levels (Fig. 6c), but it drastically reduced full-length APP levels, as well as APP-CTF in cell extracts (Fig. 6d). In the supernatant, the levels of sAPP $\alpha$, $A P P \beta$, and soluble A $\beta$ decreased in transfected CHO-PS70 cells compared to mock-transfected cells (Fig. 6e). Interestingly, when lysosomal function was impaired by chloroquine, full-length APP and sAPP $\alpha$ levels increased in a significant manner with regard to non-treated cells $(p=0.0044 ; p=0.031$, respectively, $t$-test; Fig. 7). sAPP $\beta$ levels showed a tendency to be higher than non-treated cells $(p=0.065)$.

To determine in more detail whether LRP3 is involved in APP degradation by lysosomes, we performed a differential centrifugation of CHO-PS70 cell homogenates. Two different fractions were obtained: a cytosol and plasma membrane-containing fraction, and an intracellular membrane-containing fraction. In $\mathrm{CHO}$ cells overexpressing LRP3, full-length APP levels were lower in both fractions, but APP-CTF levels were lower only in the intracellular membrane-containing fractions compared to those in $\mathrm{CHO}$ controls (Fig. 8a). Treatment with chloroquine did not affect APP levels in $\mathrm{CHO}$ cell controls in any fraction (Fig. 8b). In CHO cells overexpressing LRP3, full-length APP and APP-CTF levels increased in the cytosol and plasma membrane-containing fractions after chloroquine treatment. This could indicate that chloroquine is affecting LRP3 capacity of inducing APP endocytosis from the plasma membrane as observed in Fig. 8a. However, only APP-CTF levels were higher than those in $\mathrm{CHO}$ controls in the intracellular membrane-containing fractions (Fig. 8c). This could indicate an accumulation of APP-CTF in vesicles such as endosomes or autophagosomes, whose fusion with lysosomes is inhibited by chloroquine.

\section{Discussion}

Our results suggest that reelin signaling, through the cleavage of its receptor ApoER2, can ultimately influence the expression of other liporeceptors, such as LRP3. 


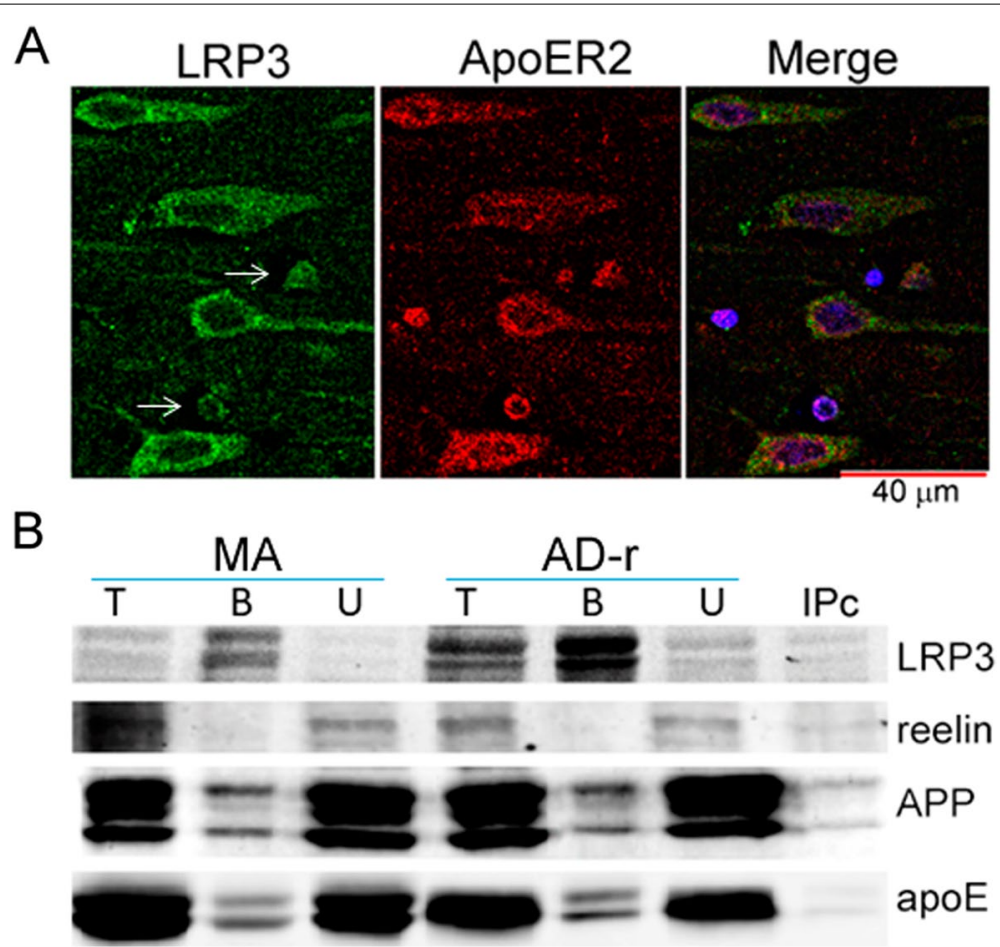

Fig. 5 LRP3 co-immunoprecipitates with apoE and APP. a Representative immunofluorescence photomicrograph showing LRP3 and ApoER2 labeling in the same cells in a hippocampus slice of a MA subject. Neurons (large cells) show LRP3 and ApoER2 co-localization; in addition, oligodendroglia-like cells (thin arrows) also co-localize both antibodies. b Representative western blots showing immunoprecipitation of LRP3 and co-immunoprecipitation of reelin (no immunoprecipitation), apoE, and APP, from non-demented (ND) and Alzheimer's disease (AD) extracts. T total input, $\mathrm{B}$ bound fraction, $\mathrm{U}$ unbound fraction, IPC bound fraction of the negative control

Many LDL receptor family members, such as ApoER2, LDLR, LRP1, LRP1b, LRP6, and SorLA (LRP11), as well as other alternative apoE receptors such as Trem2, are $\gamma$-secretase substrates $[28,29]$. For many of these receptors, the nuclear translocation of the respective ICDs and their transcriptional functions have been demonstrated or inferred [13, 30-32]. Here, we demonstrate that reelininduced generation of ApoER2-ICD, as well as ApoER2ICD overexpression, increases LRP3 expression. This supports a link between ApoER2 processing and the regulation of the alternative apoE liporeceptor LRP3.

In frontal cortex extracts from AD, where ApoER2/ reelin signaling is impaired and ApoER2 processing is lessened (reviewed in [33]), we found lower LRP3 protein and mRNA levels. LRP3 expression was mainly affected at early Braak stages of NFT pathology (stages I-II), in which the trans-entorhinal region shows neurofibrillary tangles and neuropil threads [18]. However, since the same decreasing trend was determined in advanced Braak stages, additional studies are needed to determine whether LRP3 decrease is only an early phenomenon associated to $\mathrm{AD}$-related progression.

In the microarray, after overexpression of full-length ApoER2, the expression of another LDL receptor family member, LDLR, also appears to be upregulated. Interestingly, both LRP3 and LDLR are encoded by genes located on chromosome 19, locus 19q13 [34, 35]. The $A P O E$ gene also maps in chromosome 19, on locus $19 \mathrm{q} 13.32$ [36], in a cluster together with the apolipoprotein $\mathrm{C} 1$ and $\mathrm{C} 2$ genes. Genetic linkage studies suggest the presence of AD risk genes on chromosome 19 that would act in an independent manner from apoE, such as $A B C A 7$ (19p13.3) and CD33 (19q13.41) [37]. Indeed, $L D L R$ was analyzed as a potential AD risk factor, but the study concluded that the genetic variants in LDLR did not make a significant contribution to AD risk in the general population [38]. Interestingly, recent multiplex proteomics studies have identified that LDLR levels are modestly decreased in CSF from early AD patients, suggesting that this receptor could represent a new specific biomarker for AD [39]. Other genes encoding LDL receptor family members, such as LRP1, LRP1b, LRP2, LRP4, LRP6, and SorLA, have been associated to AD risk (reviewed in [13]), as well as ApoER2 [40]. Despite the results from the microarray study, the $q \mathrm{RT}$ PCR failed to corroborate the modulation of LDLR by ApoER2 and did not find changes on LDLR expression in $\mathrm{AD}$ extracts. 


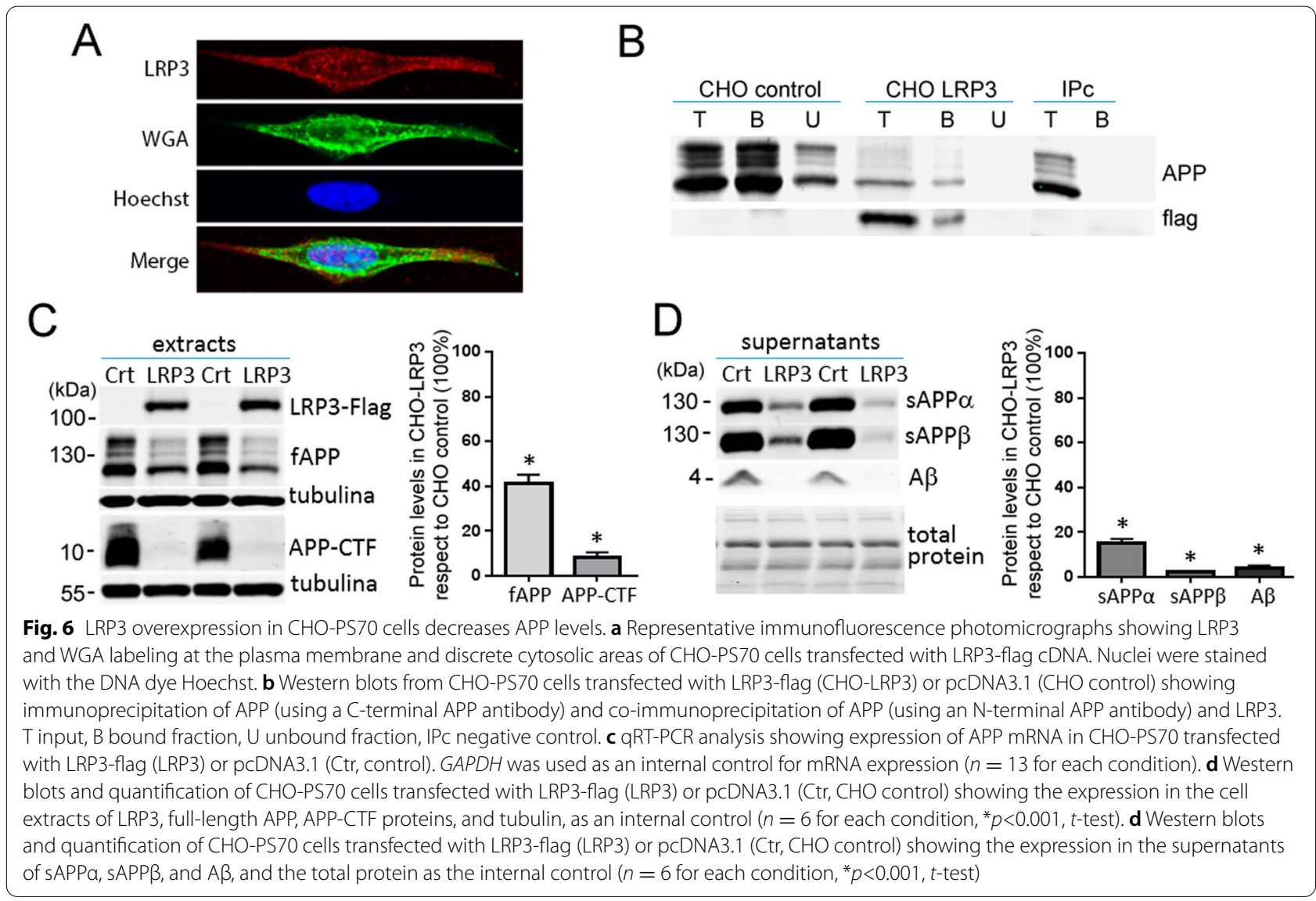

The reelin receptors ApoER2 and VLDLR are core members of the LDL family that share the same extracellular domain structure, the ligand binding-type repeat domains (LBDs) and the EGF-precursor homology domains. The intracellular domain of each of the core members contains at least one NPxY (Asn-Pro-X-Tyr) motif, which plays a role in protein interaction/signal transduction [41-43] and endocytosis [44]. In comparison, LRP3 is smaller than the core members of the LDL receptor family. LRP3 belongs to a subfamily, together with LRP10 (murine LRP9), LRP12, and Lrad3 (ST7/ Mig13). These subfamily members are characterized by the sole presence of LBDs and CUB-domains (which binds Complement, Uegf, and Bmp1) in their extracellular domain and lack the EGF-like repeats [13]. The short LBD in LRP3 is likely the domain responsible for the co-immunoprecipitation of apoE, as this is the competent region that binds several ligands [45]. However, reelin did not co-immunoprecipitate, in the same manner as receptor-associated protein (RAP), another ApoER2 ligand, which does not bind to LRP3 either [17, 34, 45, 46]. In the intracellular domain, LRP3 lacks the NPxY motifs, but instead contains a similar tyrosine-based sequence (EDFPVY) [34, 47]. Therefore, the domain by which APP is able to interact with LRP3 is yet to be determined. In vitro data showed that the extracellular domain of LRP10 interacts with APP [48], while Lrad3, the LDL receptor family member with the shortest extracellular domain [49], is also able to interact with APP and to modulate APP processing pathways. ApoER2 and APP are linked extracellularly by binding different domains of F-spondin [50] and intracellularly through the adaptor proteins Dab-1 and Fe65, which interact with the NPxY motif of ApoER2 and APP [24, 51, 52]. Therefore, more studies are needed to explore the direct or indirect interaction between LRP3 and APP.

We observed that overexpression of LRP3 decreased the levels of full-length APP and APP-CTF in the fraction containing the plasma membrane, as well as $A \beta$ and soluble APP fragment levels generated after amyloidogenic and non-amyloidogenic processing pathways. In CHO-PS70 cells overexpressing LRP3, chloroquine treatment increased the levels of full-length APP and APP-CTF in the fraction containing the plasma membrane, and of SAPP $\alpha$ in the media; furthermore, APPCTF levels in the fraction containing intracellular vesicles were higher when autophagy was inhibited compared to non-treated cells. This suggests that LRP3, described as 

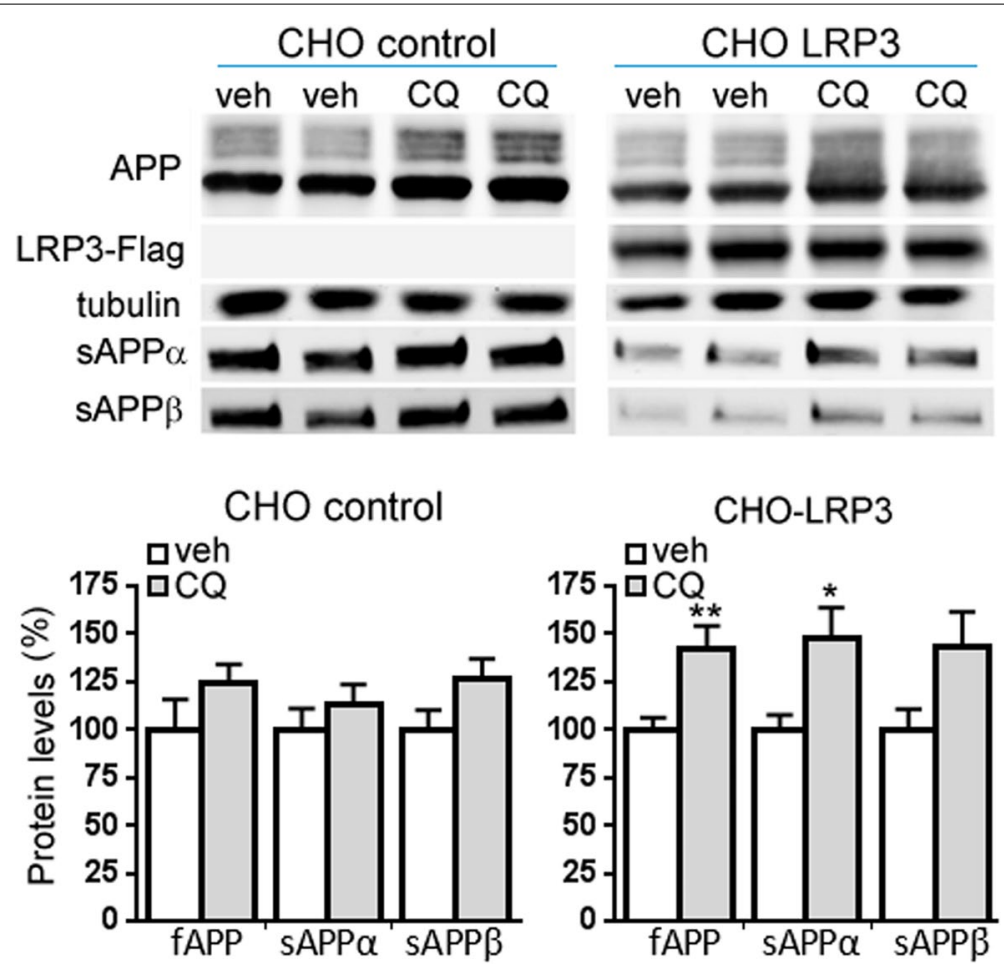

Fig. 7 Inhibition of lysosomal/autophagy function increases APP and SAPP levels. Western blots and quantification of CHO-PS70 cells transfected with LRP3-flag (CHO LRP3) or pcDNA3.1 (CHO) for 24h and then treated with $10 \mathrm{mM}$ chloroquine (CQ) for another $24 \mathrm{~h}$ or with vehicle (veh, Hank's media). Western blots show the expression in the cell extracts of LRP3, full-length APP (fAPP), and tubulin, and the expression of SAPPa and sAPP $\beta$ from the supernatants $\left(n=6-14\right.$ for each condition, ${ }^{* *} p<0.01$ for fAPP respect to control; ${ }^{* *} p<0.05$ for sAPPa respect to control; $p=0.065$ for SAPP $\beta$ )

an endocytosis receptor [34], could be involved in APP processing through lysosomal degradation/autophagy mechanisms. The blockage of LRP3-mediated APP internalization by chloroquine could explain the increase in sAPP $\alpha$ levels, but not sAPP $\beta$, as it has been proposed that the cleavage of APP by $\alpha$-secretase occurs mainly at the cell surface [53], and also the increase of APP-CTF in intracellular vesicles, as endosomes would not be able to fuse with autophagosomes, thus leading to the accumulation of APP-CTF. Core members of the LDL receptor family have also been associated with APP trafficking and internalization, thus determining APP proteolytic processing and $A \beta$ production, which could play a role in $A D$ pathogenesis [54-57]. For example, LRP1 increases APP endocytosis and generation of $A \beta$ [58-60], while LRP1B retains APP at the cell surface [61]. ApoER2 is able to alter APP subcellular distribution, increasing the generation of $A \beta$; this effect depends on the integrity of the NPxY motif in ApoER2 [62]. In a mouse model in which the ApoER2 isoform lacks three LBDs, the non-amyloidogenic processing of APP predominates [63]. In this line, LRP1 endocytosis impairment favors non-amyloidogenic processing of APP due to reduced internalization, resulting in less extracellular $A \beta[64,65]$. Additionally, mechanisms related to the APP secretory pathways are also possible, such as for LRP1, whose retention in the endoplasmic reticulum by the expression of a specific motif leads to a decrease in full-length APP and CTF levels at the plasma membrane as well as in $A \beta$ secretion [1, 66]. A direct downregulation of APP mRNA would be unlikely given our $q$ RT-PCR data.

Interestingly, LRP1 has been shown to constitute a major regulator of tau uptake and spread [67]. Therefore, the potential tau-LRP3 interactions appear to be an interesting possibility to study. A thorough investigation of possible interactions of LRP3 with AD hallmarks and key proteins could serve to decipher the physiological role and potential participation in pathological processes of this LDL receptor family member.

LRP3 expression is highest in skeletal muscle and in the ovaries, but it is also present at relatively high levels in the brain and heart, among other tissues [17]. LRP3 has been involved so far in osteogenic and adipocytic differentiation [68], and systemic use of steroids has been associated with site-specific differential methylation of the LRP3 gene [69], but its role in neuronal 
A
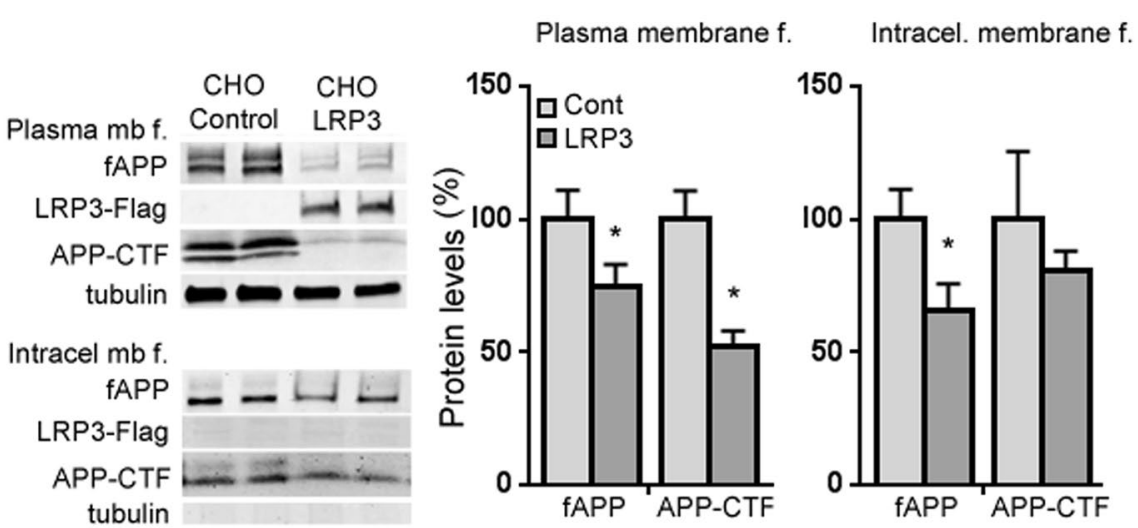

B
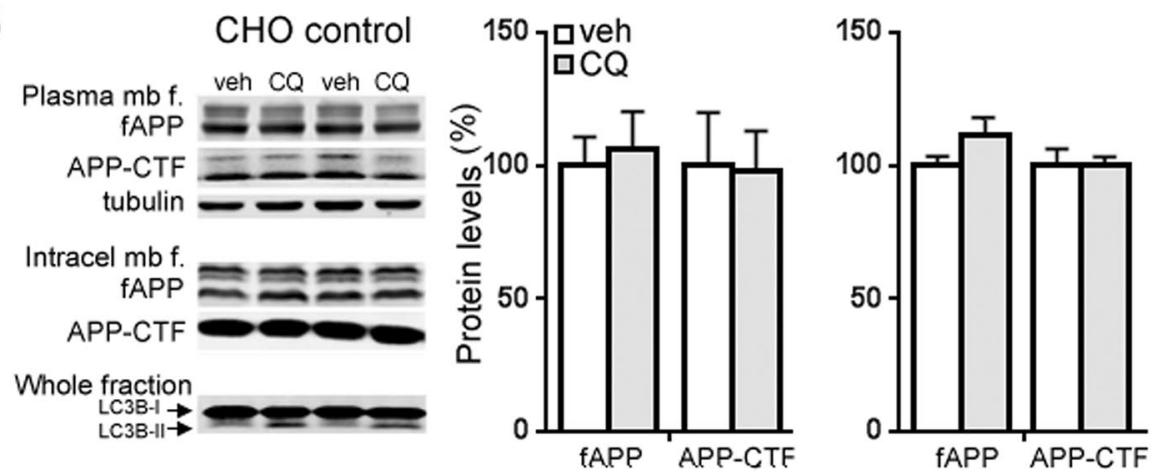

C
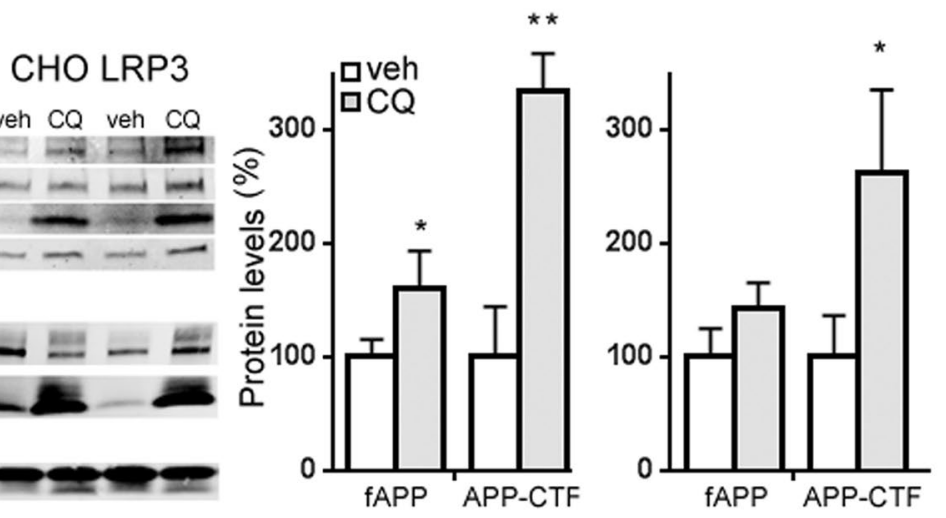

Fig. 8 Chloroquine increases full-length APP and SAPP levels at the membrane fraction. Western blots and quantification of the expression of full-length APP (fAPP), APP-CTF, Flag (LRP3-flag), and tubulin in cytosol and plasma membrane-containing fractions (plasma membrane f. or plasma $\mathrm{mb}$ f.) and in intracellular membrane-containing fractions (intracell membrane f. or intracell mb f.) from CHO-PS70 cell homogenates. The presence of LRP3-flag was only observed in the cytosol and plasma membrane fraction, and tubulin was not present in the intracellular membrane-containing fraction. For LC3B-I conversion to LC3B-II to monitor autophagy, the whole cell extracts were used. a Comparison between CHO-PS70 cells transfected with LRP3-flag (CHO LRP3) or pCDNA3.1 (CHO control). b Comparison between CHO cells transfected with pcDNA3.1 ( $\mathrm{CHO}$ control) for $24 \mathrm{~h}$ and then treated with $10 \mathrm{mM}$ chloroquine (CQ) for another $24 \mathrm{~h}$ or with vehicle (veh, Hank's media). c Comparison between $\mathrm{CHO}$ cells transfected with LRP3-flag (CHO LRP3) for $24 \mathrm{~h}$ and then treated with $10 \mathrm{mM}$ chloroquine (CQ) for another $24 \mathrm{~h}$ or with vehicle (veh, Hank's media). $\left(n=6-10\right.$ for each condition, ${ }^{* *} p<0.01 ;{ }^{*} p<0.05 t$-test $)$

activity is still unknown. LRP3 has been identified as a gene upregulated for a short window of $2 \mathrm{~h}$, exclusively following learning, in the rat dentate gyrus [70]. To clarify LRP3s biological functions, it is essential to define the significance of LRP3 expression in the brain in aging and AD-related pathology with disease progression. An alteration in the expression of LRP3 may influence the processing and expression of APP, 
affecting its synaptic function and, therefore, contributing to the $\mathrm{AD}$ pathology.

\section{Conclusions}

ApoER2/reelin signaling is able to regulate LRP3 expression, and LRP3 reduces APP protein levels, including sAPP fragments and $A \beta$ peptide. The mechanism involved is yet to be determined, although it may be related to APP endocytosis. This study could contribute to find new strategies in aging and $\mathrm{AD}$ research, given that LRP3 modulation could participate in the regulation of $A \beta$ levels.

\section{Limitations}

The main limitation of this study is the scarce knowledge of the physiological function of LRP3 in the brain, as there are few reports about it as a neuronal receptor. We employed a well-characterized brain collection, but it would be interesting to validate our findings with an alternative collection of post-mortem cortex samples from MA individuals and cases with AD-related pathology. Despite the difference in age between nondemented and control subjects, age does not appear to be related with decreased LRP3 expression in the ADrelated pathological group, but the validation of the data in age-matched groups is desirable. Development of in vivo knockouts or knockdowns of LRP3 would contribute to the understanding of the mechanism that links this receptor and APP, given that, for example, knockdown of LRP10 led to increased processing of APP to generate $A \beta[48]$.

\section{Abbreviations \\ Aß42: $\beta$-Amyloid protein (amino acid residues 1-42); AD: Alzheimer's disease; APP: Amyloid $\beta$ precursor protein; ApoE: Apolipoprotein E; ApoER2/LRP8: Apolipoprotein E receptor 2; ApoER2-ICD: ApoER2 intracytoplasmic domain; ApoER2-CTF: ApoER2 C-terminal fragment; CQ: Chloroquine; LDLR: Low- density lipoprotein receptor; ND: Non-demented; VLDLR: Very low-density lipoprotein receptor.}

\section{Supplementary Information}

The online version contains supplementary material available at https://doi. org/10.1186/s13195-021-00921-5.

Additional file 1: Supplemental Figure 1. Representatives whole blots Whole blots from SH-SY5Y cell extracts, human frontal cortex from nondemented and Alzheimer's disease subjects, and from $\mathrm{CHO}$ cell extracts and supernatants. The antibody employed in every blot is indicated. $T=$ total input, $B=$ bound fraction, $U=$ unbound fraction, $B c$ : bound fraction of the negative control, Uc: bound fraction of the negative control.

Additional file 2. Complete microarray.

\section{Acknowledgements}

We thank Prof. T. Curran (Eppley Institute, University of Nebraska Medical Center, Omaha, USA), J. Nimpf (Max F., Department of Medical Biochemistry, Medical University of Vienna, Austria), W. Rebeck (Georgetown University Medical Center, Washington, D.C., USA), and C. Lavoie (Department of Pharmacology and Physiology, University of Sherbrooke, Québec, Canada) for generously providing CDNAs. We thank Dr. E. Soriano and L. Pujadas (Department of Cell Biology, University of Barcelona, Barcelona, Spain) for providing HEK-293T cells stably transfected with reelin CDNA and GFP. We thank Pol Andres-Benito and Margarita Carmona (Department of Pathology and Experimental Therapeutics, University of Barcelona) for technical help.

\section{Code availability \\ Not applicable.}

\section{Authors' contributions}

Conceptualization: JS-V and IC-I. Formal analysis and investigation: IC-I, ML, SE, IL-F, TM, and LV-V. Human brain source and analysis: IF. Writing of the original draft preparation: JS-V and IC-I. Writing, review, and editing: all authors. Funding acquisition: JS-V. The author(s) read and approved the final manuscript.

\section{Funding}

This work was supported by grants from the Fondo de Investigaciones Sanitarias (PI15/00665 and PI19-01359, co-funded by the Fondo Europeo de Desarrollo Regional, FEDER "Investing in your future"), CIBERNED (Instituto de Salud Carlos III, Spain) and from the Direcció General de Ciència i Investigació, Generalitat Valenciana (AICO/2021/308). We also acknowledge financial support from the Spanish Ministerio de Economía y Competitividad, through the "Severo Ochoa" Programme for Centres of Excellence in R\&D (SEV-2017-0723).

\section{Availability of data and materials}

All data and materials support their published claims and comply with field standards.

\section{Declarations}

\section{Ethics approval and consent to participate}

This study was approved by the ethics committee of Universidad Miguel Hernández de Elche, Spain, and it was carried out in accordance with the Declaration of Helsinki.

\section{Ethical standards}

The experiments comply with the current laws of the country in which they were performed, Spain.

Consent for publication

Not applicable.

\section{Competing interests}

The authors declare that they have no competing interests.

\section{Author details}

${ }^{1}$ Instituto de Neurociencias de Alicante, Universidad Miguel Hernández de Elche-CSIC, Sant Joan d'Alacant, Spain. ${ }^{2}$ Centro de Investigación Biomédica en Red sobre Enfermedades Neurodegenerativas (CIBERNED), Madrid, Spain. ${ }^{3}$ Instituto de Investigación Sanitaria y Biomédica de Alicante (ISABIAL), Alicante, Spain. ${ }^{4}$ Instituto de Neuropatología, Hospital Universitario de Bellvitge, Universidad de Barcelona, Hospitalet de Llobregat, Barcelona, Spain.

Received: 10 February 2021 Accepted: 19 October 2021

Published online: 02 November 2021

\section{References}

1. Waldron E, Heilig C, Schweitzer A, Nadella N, Jaeger S, Martin AM, et al. LRP1 modulates APP trafficking along early compartments of the secretory pathway. Neurobiol Dis. 2008;31:188-97 Available from: https:// pubmed.ncbi.nlm.nih.gov/18559293/. Cited 2020 Dec 27. 
2. Gilat-Frenkel M, Boehm-Cagan A, Liraz O, Xian X, Herz J, Michaelson DM. Involvement of the Apoer 2 and Lrp1 receptors in mediating the pathological effects of ApoE4 in vivo. Curr Alzheimer Res. 2014;11:549-57 Bentham Science Publishers Ltd. Available from: http://www.ncbi.nIm. nih.gov/pubmed/24251389. Cited 2020 Feb 13.

3. Kim J, Yoon H, Basak J, Kim J. Apolipoprotein E in synaptic plasticity and Alzheimer's disease: potential cellular and molecular mechanisms. Mol Cells. 2014:833-40 Korean Society for Molecular and Cellular Biology. Available from: http://www.ncbi.nlm.nih.gov/pubmed/25358504. Cited 2020 Feb 13.

4. Bock HH, May P. Canonical and non-canonical reelin signaling. Front Cell Neurosci. 2016;10:166 Frontiers Media S.A. Available from: http://www. ncbi.nlm.nih.gov/pubmed/27445693. Cited 2020 Feb 13

5. Lane-Donovan C, Herz J. Building a better blood-brain barrier. Elife. 2017;6:e31808 eLife Sciences Publications Ltd. Available from: http:// www.ncbi.nlm.nih.gov/pubmed/28994392. Cited 2020 Feb 13.

6. May P, Herz J, Bock HH. Molecular mechanisms of lipoprotein receptor signalling. Cell Mol Life Sci. 2005;62(19-20):2325-38 Springer. Available from: https://link.springer.com/article/10.1007/s00018-005-5231-z. Cited 2021 Jan 18.

7. Herz J, Chen Y. Reelin, lipoprotein receptors and synaptic plasticity. Nat Rev Neurosci. 2006;(7):850-9 Available from: http://www.ncbi.nlm.nih. gov/pubmed/17053810. Cited 2019 Jul 23.

8. Schmechel DE, Saunders AM, Strittmatter WJ, Crain BJ, Hulette CM, Joo $\mathrm{SH}$, et al. Increased amyloid $\beta$-peptide deposition in cerebral cortex as a consequence of apolipoprotein E genotype in late-onset Alzheimer disease. Proc Natl Acad Sci U S A. 1993;90:9649-53 National Academy of Sciences.

9. Pinto D, Delaby E, Merico D, Barbosa M, Merikangas A, Klei L, et al. Convergence of genes and cellular pathways dysregulated in autism spectrum disorders. Am J Hum Genet. 2014;94:677-94 Available from: https://linki nghub.elsevier.com/retrieve/pii/S0002929714001505. Cited 2019 Jan 14.

10. Jaeger S, Pietrzik CU. Functional role of lipoprotein receptors in Alzheimer's disease. Curr Alzheimer Res. 2008;5:15-25 Available from: http:// www.ncbi.nlm.nih.gov/pubmed/18288927. Cited 2020 Feb 13.

11. Marzolo MP, Bu G. Lipoprotein receptors and cholesterol in APP trafficking and proteolytic processing, implications for Alzheimer's disease. Semin Cell Dev Biol. 2009;20(2):191-200 Elsevier Ltd. Available from: http://www.ncbi.nlm.nih.gov/pubmed/19041409. Cited 2020 Feb 13.

12. Lane-Donovan C, Philips GT, Herz J. More than cholesterol transporters: lipoprotein receptors in CNS function and neurodegeneration. Neuron. 2014;83:771-87 Available from: http://www.ncbi.nlm.nih.gov/pubmed/ 25144875. Cited 2020 Feb 13.

13. Pohlkamp T, Wasser CR, Herz J. Functional roles of the interaction of APP and lipoprotein receptors. Front Mol Neurosci. 2017;10:54 Frontiers Media S.A. Available from: http://www.ncbi.nlm.nih.gov/pubmed/28298885. Cited 2020 Feb 13.

14. Balmaceda V, Cuchillo-Ibáñez I, Pujadas L, García-Ayllón M-S, Saura CA, Nimpf J, et al. ApoER2 processing by presenilin-1 modulates reelin expression. FASEB J. 2014;28(4):1543-54.

15. Telese F, Ma Q, Perez PM, Notani D, Oh S, Li W, et al. LRP8-reelin-regulated neuronal enhancer signature underlying learning and memory formation. Neuron. 2015;86:696-710 Cell Press. Available from: http://www. ncbi.nlm.nih.gov/pubmed/25892301. Cited 2020 Feb 13.

16. Mata-Balaguer T, Cuchillo-Ibañez I, Calero M, Ferrer I, Sáez-Valero J. Decreased generation of C-terminal fragments of ApoER2 and increased reelin expression in Alzheimer's disease. FASEB J. 2018;32:3536-46 Available from: https://www.fasebj.org/doi/10.1096/fj.201700736RR. Cited 2019 Jan 10.

17. Battle MA, Maher VM, McCormick JJ. ST7 is a novel low-density lipoprotein receptor-related protein (LRP) with a cytoplasmic tail that interacts with proteins related to signal transduction pathways. Biochemistry. 2003;42:7270-82 Available from: http://pubs.acs.org/doi/abs/10.1021/ bi034081y. Cited 2019 Feb 22

18. Braak H, Braak E. Neuropathological stageing of Alzheimer-related changes. Acta Neuropathol. 1991;82:239-59 Available from: http://www. ncbi.nlm.nih.gov/pubmed/1759558. Cited 2019 Jul 15.

19. Braak H, Alafuzoff I, Arzberger T, Kretzschmar H, Del Tredici K. Staging of Alzheimer disease-associated neurofibrillary pathology using paraffin sections and immunocytochemistry. Acta Neuropathol.
2006;112:389-404 Available from: http://www.ncbi.nlm.nih.gov/pubmed/16906426. Cited 2019 Jul 15.

20. Ferrer I. Defining Alzheimer as a common age-related neurodegenerative process not inevitably leading to dementia. Prog Neurobiol. 2012;97:3851 Available from: https://pubmed.ncbi.nlm.nih.gov/22459297/. Cited 2021 Sep 27.

21. Chen Y, Kundakovic M, Agis-Balboa RC, Pinna G, Grayson DR. Induction of the reelin promoter by retinoic acid is mediated by Sp1. J Neurochem. 2007;103:650-65 Available from: https://pubmed.ncbi.nlm.nih.gov/17666 047/. Cited 2021 Apr 8.

22. Jämsä $A$, Hasslund $K$, Cowburn RF, Bäckström $A$, Vasänge $M$. The retinoic acid and brain-derived neurotrophic factor differentiated SH-SY5Y cell line as a model for Alzheimer's disease-like tau phosphorylation. Biochem Biophys Res Commun. 2004;319:993-1000 Available from: https://pubmed.ncbi.nlm.nih.gov/15184080/. Cited 2021 Apr 12.

23. Dumanis SB, Cha HJ, Song JM, Trotter JH, Spitzer M, Lee JY, et al. ApoE receptor 2 regulates synapse and dendritic spine formation. PLoS One. 2011;6(2):e17203 Available from: https://pubmed.ncbi.nlm.nih.gov/21347 244/. Cited 2021 Mar 22.

24. Hoe H-S, Wessner D, Beffert U, Becker AG, Matsuoka Y, Rebeck GW. F-spondin interaction with the apolipoprotein E receptor ApoEr2 affects processing of amyloid precursor protein. Mol Cell Biol. 2005;25:9259-68 Available from: http://www.ncbi.nlm.nih.gov/pubmed/16227578. Cited 2020 Feb 14.

25. Xia W, Zhang J, Kholodenko D, Citron M, Podlisny MB, Teplow DB, et al. Enhanced production and oligomerization of the 42 -residue amyloid $\beta$ protein by Chinese hamster ovary cells stably expressing mutant presenilins. J Biol Chem. 1997;272:7977-82 American Society for Biochemistry and Molecular Biology. Available from: http://www-jbc.stanford.edu/jbc/. Cited 2020 Dec 26.

26. Brodeur J, Larkin H, Boucher R, Thériault C, St-Louis SC, Gagnon H, et al. Calnuc binds to LRP9 and affects its endosomal sorting. Traffic. 2009;10:1098-114 Blackwell Munksgaard. Available from: https://pubmed.ncbi.nlm.nih.gov/19497050/. Cited 2020 Dec 26.

27. Calero O, García-Albert L, Rodríguez-Martín A, Veiga S, Calero M. A fast and cost-effective method for apolipoprotein e isotyping as an alternative to APOE genotyping for patient screening and stratification. Sci Rep. 2018;8(1):1-8 Nature Publishing Group. Available from: https://pubmed. ncbi.nlm.nih.gov/29654261/. Cited 2021 Jun 15.

28. Lleó A, Saura CA. $Y$-secretase substrates and their implications for drug development in Alzheimer's disease. Curr Top Med Chem. 2011;11:151327 Available from: http://www.ncbi.n/m.nih.gov/pubmed/21510835. Cited 2020 Feb 13.

29. Güner G, Lichtenthaler SF. The substrate repertoire of $\gamma$-secretase/presenilin. Semin Cell Dev Biol. 2020;105:27-42 Elsevier Ltd.

30. Mi K, Johnson GVW. Regulated proteolytic processing of LRP6 results in release of its intracellular domain. J Neurochem. 2007:101:517-29 Available from: http://www.ncbi.nlm.nih.gov/pubmed/17326769. Cited 2020 Feb 13.

31. May P, Woldt E, Matz RL, Boucher P. The LDL receptor-related protein (LRP) family: an old family of proteins with new physiological functions. Ann Med. 2007;39:219-28 Available from: http://www.ncbi.nlm.nih.gov/ pubmed/17457719. Cited 2020 Feb 13.

32. Wakabayashi T, De Strooper B. Presenilins: members of the $\gamma$-secretase quartets, but part-time soloists too. Physiology. 2008;23(4):194-204 Physiology (Bethesda). Available from: https://pubmed.ncbi.nlm.nih.gov/ 18697993/. Cited 2020 Dec 26.

33. Cuchillo-Ibañez I, Balmaceda V, Mata-Balaguer T, Lopez-Font I, Sáez-Valero $J$. Reelin in Alzheimer's disease, increased levels but impaired signaling: when more is less. J Alzheimer's Dis. 2016;52:403-16 Available from: http://www.medra.org/servlet/aliasResolver?alias=iospress\&doi=10. 3233/JAD-151193. Cited 2019 Mar 28.

34. Ishii H, Kim D-H, Fujita T, Endo Y, Saeki S, Yamamoto TT. cDNA cloning of a new low-density lipoprotein receptor-related protein and mapping of its gene (LRP3) to chromosome bands 19q12-q13.2. Genomics. 1998;51:132-5 Available from: http://www.ncbi.nlm.nih.gov/pubmed/ 9693042. Cited 2019 Feb 22.

35. Francke U, Brown MS, Goldstein JL. Assignment of the human gene for the low density lipoprotein receptor to chromosome 19: synteny of a receptor, a ligand, and a genetic disease. Proc Natl Acad Sci U S A. 1984;81:2826-30. 
36. Shaw DJ, Brook JD, Meredith AL, Harley HG, Sarfarazi M, Harper PS. Gene mapping and chromosome 19. J Med Genet. 1986;23:2-10 Available from: http://www.ncbi.nlm.nih.gov/pubmed/3081724. Cited 2020 Feb 14.

37. Moreno-Grau S, Hernández I, Heilmann-Heimbach S, Ruiz S, RosendeRoca M, Mauleón A, et al. Genome-wide significant risk factors on chromosome 19 and the APOE locus. Oncotarget. 2018;9:24590-600 Impact Journals LLC. Available from: http://www.ncbi.n/m.nih.gov/pubmed/ 29872490. Cited 2020 Feb 14.

38. Bertram L, Hsiao M, McQueen MB, Parkinson M, Mullin K, Blacker D, et al. The LDLR locus in Alzheimer's disease: a family-based study and metaanalysis of case-control data. Neurobiol Aging. 2007;28:18.e1-4 Elsevier Inc. Available from: http://www.ncbi.nlm.nih.gov/pubmed/16378661. Cited 2020 Feb 14.

39. Whelan CD, Mattsson N, Nagle MW, Vijayaraghavan S, Hyde C, Janelidze S, et al. Multiplex proteomics identifies novel CSF and plasma biomarkers of early Alzheimer's disease. Acta Neuropathol Commun. 2019;7:169 BioMed Central Ltd. Available from: http://www.ncbi.nlm.nih.gov/pubmed/31694 701. Cited 2020 Feb 14.

40. Ma SL, Ng HK, Baum L, Pang JCS, Chiu HFK, Woo J, et al. Low-density lipoprotein receptor-related protein 8 (apolipoprotein E receptor 2) gene polymorphisms in Alzheimer's disease. Neurosci Lett. 2002;332:216-8 Elsevier Ireland Ltd.

41. Trommsdorff M, Borg JP, Margolis B, Herz J. Interaction of cytosolic adaptor proteins with neuronal apolipoprotein $\mathrm{E}$ receptors and the amyloid precursor protein. J Biol Chem. 1998;273:33556-60

42. Howell BW, Lanier LM, Frank R, Gertler FB, Cooper JA. The disabled 1 phosphotyrosine-binding domain binds to the internalization signals of transmembrane glycoproteins and to phospholipids. Mol Cell Biol. 1999:19:5179-88 American Society for Microbiology. Available from: https://pubmed.ncbi.nIm.nih.gov/10373567/. Cited 2020 Dec 20

43. Gotthardt M, Trommsdorff M, Nevitt MF, Shelton J, Richardson JA, Stockinger W, et al. Interactions of the low density lipoprotein receptor gene family with cytosolic adaptor and scaffold proteins suggest diverse biological functions in cellular communication and signal transduction. J Biol Chem. 2000;275:25616-24.

44. Chen WJ, Goldstein JL, Brown MS. NPXY, a sequence often found in cytoplasmic tails, is required for coated pit-mediated internalization of the low density lipoprotein receptor. J Biol Chem. 1990;265:3116-23.

45. Croy JE, Shin WD, Knauer MF, Knauer DJ, Komives EA. All three LDL receptor homology regions of the LDL receptor-related protein bind multiple ligands. Biochemistry. 2003:42:13049-57 Available from: http://pubs.acs. org/doi/abs/10.1021/bi034752s. Cited 2019 Feb 22

46. Divekar SD, Burrell TC, Lee JE, Weeber EJ, Rebeck GW. Ligand-induced homotypic and heterotypic clustering of apolipoprotein E receptor 2. J Biol Chem. 2014;289:15894-903 American Society for Biochemistry and Molecular Biology Inc. Available from: https://pubmed.ncbi.nlm.nih.gov/ 24755222/. Cited 2020 Dec 20

47. Boucher R, Larkin H, Brodeur J, Gagnon H, Thériault C, Lavoie C. Intracellular trafficking of LRP9 is dependent on two acidic cluster/ dileucine motifs. Histochem Cell Biol. 2008;130:315-27 Springer Verlag. Available from: https://pubmed.ncbi.nlm.nih.gov/18461348/. Cited 2020 Aug 6.

48. Brodeur J, Thériault C, Lessard-Beaudoin M, Marcil A, Dahan S, Lavoie C. LDLR-related protein 10 (LRP10) regulates amyloid precursor protein (APP) trafficking and processing: evidence for a role in Alzheimer's disease. Mol Neurodegener. 2012;7:31 Available from: https://pubmed.ncbi. nlm.nih.gov/22734645/. Cited 2020 Jul 30.

49. Ranganathan S, Noyes NC, Migliorini M, Winkles JA, Battey FD, Hyman BT, et al. LRAD3, a novel low-density lipoprotein receptor family member that modulates amyloid precursor protein trafficking. J Neurosci. 2011;31:10836-46 Available from: https://pubmed.ncbi.nlm.nih.gov/ 21795536/. Cited 2020 Dec 26

50. Ho A, Südhof TC. Binding of F-spondin to amyloid- $\beta$ precursor protein: a candidate amyloid- $\beta$ precursor protein ligand that modulates amyloid- $\beta$ precursor protein cleavage. Proc Natl Acad Sci U S A. 2004;101:2548-53.

51. May P, Krishna Reddy Y, Herz J. Proteolytic processing of low density lipoprotein receptor-related protein mediates regulated release of its intracellular domain. J Biol Chem. 2002;277:18736-43 Available from: https://pubmed.ncbi.nlm.nih.gov/11907044/. Cited 2020 Aug 4.
52. Hoe HS, Tran TS, Matsuoka Y, Howell BW, Rebeck GW. DAB1 and reelin effects on amyloid precursor protein and ApoE receptor 2 trafficking and processing. J Biol Chem. 2006;281:35176-85 JBC Papers in Press. Available from: http://www.jbc.org/. Cited 2020 Dec 20.

53. Evrard C, Kienlen-Campard P, Coevoet M, Opsomer R, Tasiaux B, Melnyk P, et al. Contribution of the endosomal-lysosomal and proteasomal systems in amyloid- $\beta$ precursor protein derived fragments processing. Front Cell Neurosci. 2018;12:435 Frontiers Media S.A. Available from: www.front iersin.org. Cited 2021 Jun 5.

54. Kounnas MZ, Moir RD, Rebeck GW, Bush Al, Argraves WS, Tanzi RE, et al. $L D L$ receptor-related protein, a multifunctional ApoE receptor, binds secreted $\beta$-amyloid precursor protein and mediates its degradation. Cell. 1995:82:331-40.

55. Bu G, Cam J, Zerbinatti C. LRP in amyloid-beta production and metabolism. Ann NY Acad Sci. 2006;1086:35-53 Available from: http://www.ncbi. nlm.nih.gov/pubmed/17185504. Cited 2020 Feb 14.

56. Holtzman DM, Herz J, Bu G. Apolipoprotein E and apolipoprotein E receptors: normal biology and roles in Alzheimer disease. Cold Spring Harb Perspect Med. 2012;2:a006312 Cold Spring Harbor Laboratory Press. Available from: http://www.ncbi.nlm.nih.gov/pubmed/22393530. Cited 2020 Feb 14.

57. Zhang H, Chen W, Tan Z, Zhang L, Dong Z, Cui W, et al. A role of lowdensity lipoprotein receptor-related protein 4 (LRP4) in astrocytic $A \beta$ clearance. J Neurosci. 2020;40:JN-RM-0250-20 Society for Neuroscience. Available from: https://pubmed.ncbi.nlm.nih.gov/32457076/. Cited 2020 Jul 30.

58. Ulery PG, Beers J, Mikhailenko I, Tanzi RE, Rebeck GW, Hyman BT, et al. Modulation of $\beta$-amyloid precursor protein processing by the low density lipoprotein receptor-related protein (LRP). Evidence that LRP contributes to the pathogenesis of Alzheimer's disease. J Biol Chem. 2000:275:7410-5.

59. Pietrzik CU, Busse T, Merriam DE, Weggen S, Koo EH. The cytoplasmic domain of the $L D L$ receptor-related protein regulates multiple steps in APP processing. EMBO J. 2002;21:5691-700.

60. Cam JA, Zerbinatti CV, Li Y, Bu G. Rapid endocytosis of the low density lipoprotein receptor-related protein modulates cell surface distribution and processing of the beta-amyloid precursor protein. J Biol Chem. 2005;280:15464-70 Available from: http://www.ncbi.nlm.nih.gov/ pubmed/15705569. Cited 2020 Feb 14.

61. Cam JA, Zerbinatti CV, Knisely JM, Hecimovic S, Li Y, Bu G. The low density lipoprotein receptor-related protein $1 \mathrm{~B}$ retains beta-amyloid precursor protein at the cell surface and reduces amyloid-beta peptide production J Biol Chem. 2004;279:29639-46 Available from: http://www.ncbi.nlm.nih. gov/pubmed/15126508. Cited 2020 Feb 14.

62. Fuentealba RA, Barría MI, Lee J, Cam J, Araya C, Escudero CA, et al. ApoER2 expression increases Abeta production while decreasing Amyloid Precursor Protein (APP) endocytosis: possible role in the partitioning of APP into lipid rafts and in the regulation of gamma-secretase activity. Mol Neurodegener. 2007;2:14 Available from: http://www.ncbi.nlm.nih.gov/ pubmed/17620134. Cited 2020 Feb 14.

63. Goto JJ, Tanzi RE. The role of the low-density lipoprotein receptorrelated protein (LRP1) in Alzheimer's A $\beta$ generation: development of a cell-based model system. J Mol Neurosci. 2002;19:37-41 Humana Press. Available from: http://www.ncbi.nlm.nih.gov/pubmed/12212791. Cited 2020 Apr 2.

64. Van Gool B, Storck SE, Reekmans SM, Lechat B, Gordts PLSM, Pradier L, et al. LRP1 has a predominant role in production over clearance of $A \beta$ in a mouse model of Alzheimer's disease. Mol Neurobiol. 2019:56:7234-45 Humana Press Inc. Available from: https://pubmed.ncbi.nlm.nih.gov/ 31004319/. Cited 2020 Dec 28.

65. Eggert S, Gonzalez AC, Thomas C, Schilling S, Schwarz SM, Tischer C, et al. Dimerization leads to changes in APP (amyloid precursor protein) trafficking mediated by LRP1 and SorLA. Cell Mol Life Sci. 2018;75:301-22 Birkhauser Verlag AG. Available from: https://pubmed.ncbi.nlm.nih.gov/ 28799085/. Cited 2021 Jan 18.

66. Herr UM, Strecker P, Storck SE, Thomas C, Rabiej V, Junker A, et al. LRP1 modulates APP intraneuronal transport and processing in its monomeric and dimeric state. Front Mol Neurosci. 2017:10:118 Frontiers Research Foundation. Available from: https://pubmed.ncbi.nlm.nih.gov/28496400/. Cited 2020 Dec 27 
67. Rauch JN, Luna G, Guzman E, Audouard M, Challis C, Sibih YE, et al. LRP1 is a master regulator of tau uptake and spread. Nature. 2020;580:381-5 Nature Research.

68. Elsafadi M, Manikandan M, Alajez NM, Hamam R, Dawud RA, Aldahmash A, et al. MicroRNA-4739 regulates osteogenic and adipocytic differentiation of immortalized human bone marrow stromal cells via targeting LRP3. Stem Cell Res. 2017;20:94-104 Available from: http://www.ncbi.nlm. nih.gov/pubmed/28340487. Cited 2020 Feb 14.

69. Wan ES, Qiu W, Baccarelli A, Carey VJ, Bacherman H, Rennard SI, et al. Systemic steroid exposure is associated with differential methylation in chronic obstructive pulmonary disease. Am J Respir Crit Care Med.
2012;186:1248-55 Available from: http://www.ncbi.nlm.nih.gov/pubmed/23065012. Cited 2020 Feb 14.

70. O'Sullivan NC, McGettigan PA, Sheridan GK, Pickering M, Conboy L, $\mathrm{O}^{\prime}$ Connor JJ, et al. Temporal change in gene expression in the rat dentate gyrus following passive avoidance learning. J Neurochem. 2007;101:1085-98 Available from: http://www.ncbi.nlm.nih.gov/pubmed/17298388. Cited 2020 Feb 14.

\section{Publisher's Note}

Springer Nature remains neutral with regard to jurisdictional claims in published maps and institutional affiliations.
Ready to submit your research? Choose BMC and benefit from:

- fast, convenient online submission

- thorough peer review by experienced researchers in your field

- rapid publication on acceptance

- support for research data, including large and complex data types

- gold Open Access which fosters wider collaboration and increased citations

- maximum visibility for your research: over $100 \mathrm{M}$ website views per year

At BMC, research is always in progress.

Learn more biomedcentral.com/submissions 